CUAD. CONTAB. / BOCOTÁ, COLOMBIA, 16 (41): 355-394 / MAYO-ACOSTO 2015 / 355

\title{
Elementos para discusión sobre el estado actual de la propuesta curricular del programa de contaduría pública de la Universidad de Antioquia*
}

doi:10.11144/Javeriana.cc16-41.edea

María Isabel Duque-Roldán

Contadora pública, Universidad de Antioquia. Especialista en revisoría fiscal, Universidad de Antioquia. Especialista en didáctica universitaria, Universidad de Antioquia. Maestría en ciencia política, Universidad de Antioquia. Profesora investigadora, Departamento de Ciencias Contables, Universidad de Antioquia.

Correo electrónico: isabel.duque@udea.edu.co

\section{Carlos Mario Ospina-Zapata}

Contador público, Universidad de Antioquia. Maestría en ciencias de la administración, EAFIT. Profesor investigador, Departamento de Ciencias Contables, Universidad de Antioquia.

Correo electrónico: cmario.ospina@udea.edu.co

\footnotetext{
* Este artículo se deriva de la ejecución del proyecto de investigación El currículo de contaduría pública de la Universidad de Antioquia. Comprensiones y transformaciones, inscrito en el Centro de Investigaciones de la Facultad de Ciencias Económicas, mediante Acta 8733-029-2013 y financiado por el Departamento de Ciencias Contables, de la Universidad de Antioquia. Una primera versión de este trabajo fue presentada en el IV Encuentro Nacional de Profesores de Contaduría Pública, realizado por las Universidades de Antioquia y EAFIT, en marzo de 2015. Agradecemos el diálogo propiciado para mejorar el sentido de lo expuesto.
} 
Resumen El programa de contaduría de la Universidad de Antioquia declara expresamente la utilización de un modelo pedagógico que combina elementos sociales y desarrollistas, para lo cual se configuró un diseño curricular basado en la solución de problemas, en el cual se contextualizan y problematizan todos aquellos asuntos que son relevantes en la formación del contador público en Colombia. Este enfoque requiere: 1) la utilización de didácticas activas para que el estudiante se apropie del conocimiento de manera consciente, crítica y reflexiva y no se ejerza una mera transmisión de contenidos o normas y 2) la investigación como eje articulador, como camino que enriquece el trabajo que se hace en el aula. Este artículo presenta parte de los resultados de una investigación cualitativa que tiene como objetivo determinar el cumplimiento de los fundamentos conceptuales de la transformación curricular del programa y la cual combinó la indagación directa a los estudiantes y el análisis de los microcurrículos elaborados por los profesores y de sus prácticas en el aula. El trabajo realizado permite concluir que las didácticas utilizadas en su mayoría resultan propias de modelos pedagógicos instruccionales o tradicionales, que la investigación no ha logrado permear completamente la labor realizada en el aula y que diversos componentes de la propuesta se quedan a medio camino en su ejecutoria. Esto sin desconocer que se han logrado avances importantes en la formación de contadores públicos.

Palabras clave pedagogía; currículo; didáctica; modelos pedagógicos; currículo problematizador; educación contable; formación contable

Código JEL M41, M49

\section{Elements for the Discussion on the Current Status of the Curricular Proposal of the Public Accounting Program of the Universidad de Antioquia}

Abstract The accounting program of Universidad de Antioquia explicitly declares the use of a pedagogical model that combines social and developmentalist elements. For this purpose, a problem solving curricular design was configured, in which all matters relevant to the education of public accountants in Colombia are contextualized and defined as problems. This approach requires: 1 ) the use of active didactics so the student can take knowledge in a conscious, critical, and reflective way; so there is not a mere transmission of contents or rules; and 2) research as an articulating axis, as a way that enriches the work performed in the classrooms. This article presents part of the results of a qualitative research -the purpose of which was to determine the compliance with the conceptual basis of the curricular transformation of the program- combining direct formulation of questions to students and the analysis of micro-curricula created by teachers and their classroom practices. The work performed allows us to conclude that the most used didactics correspond to traditional or instructional pedagogical models; research has not been able to completely envelope the work performed in the classroom; and that several components of the proposal have been dropped halfway through their execution. However, this is not meant to ignore that there have been important advances in the education of public accountants.

Keywords pedagogy; curriculum; didactics; pedagogical models; problem-formulation curriculum; accounting education; accounting training

\section{Elementos para discussão sobre o estado atual da proposta curricular do programa de contabilidade pública da universidade de Antioquia}

Resumo O programa de contabilidade da Universidade de Antioquia declara expressamente a utilização de um modelo pedagógico que combina elementos sociais e desenvolvimentistas, para o qual se configurou um desenho curricular baseado na solução de problemas, no qual se contextualizam e problematizam todos aqueles assuntos que são relevantes na formação do contador público na Colômbia. Este enfoque requer: 1) a utilização de didáticas ativas para que o estudante se 
aproprie do conhecimento de maneira consciente, crítica e reflexiva e não se exerça uma mera transmissão de conteúdos ou normas e 2) a pesquisa como eixo articulador, como caminho que enriquece o trabalho que se faz na sala. Este artigo apresenta parte dos resultados de uma pesquisa qualitativa que tem como objetivo determinar o cumprimento dos fundamentos conceituais da transformação curricular do programa e a qual combinou a indagação direta aos estudantes e a análise dos micro-currículos elaborados pelos professores e de suas práticas na sala. $\mathrm{O}$ trabalho realizado permite concluir que as didáticas utilizadas em sua maioria resultam próprias de modelos pedagógicos instrucionais ou tradicionais, que a pesquisa não tem conseguido permear completamente o labor realizado na sala e que diversos componentes da proposta ficam a meio caminho de sua execução. Isto sem desconhecer que se conseguiram avanços importantes na formação de contadores públicos.

Palavras-chave pedagogia; currículo; didática; modelos pedagógicos; currículo problematizador; educação contábil; formação contábil

\section{Introducción}

La evaluación curricular debe ser comprendida como un proceso permanente de investigación sobre los elementos que componen un currículo. El producto más importante de esta labor es la transformación o actualización del currículo con el objetivo de lograr cabalmente los propósitos definidos. En el caso del programa de contaduría de la Universidad de Antioquia, el modelo curricular utilizado se ha denominado problematizador o basado en la solución de problemas, el cual, según Elvia María González-Agudelo (2000), se caracteriza por:

- Trabajar con el método problémico con un método investigativo.
- Desarrollar competencias, habilidades, valores y sensibilidades de los profesionales en una forma consciente.

- Articular lo pedagógico, lo didáctico, lo curricular y lo administrativo en un modelo sistémico abierto y complejo.

- Construir un modelo de formación del profesional esencialmente investigativo en pos del desarrollo científico y humano.

- Relacionar, mediante la solución de problemas las diferentes ciencias, es decir, fundamentar el trabajo curricular sobre la posible interdisciplinariedad.

- Optimizar el proceso docente-educativo.

- Enseñar las ciencias desde su propia construcción, pero en relación con los propósitos de formación construidos por la institución docente, a partir de los problemas sociales.

- Articular la docencia con la investigación y la extensión.

- Integrar teoría y práctica, tanto desde las ciencias como desde lo profesional.

- Alcanzar procesos de intervención de la universidad en la sociedad.

- Sistematizar los conocimientos, habilidades y valores mediante un proceso docente complejo en torno al objeto de estudio de la profesión.

- Flexibilizar el currículo mediante los proyectos de aula.

- Desarrollar competencias, habilidades, valores y afectos en relación directa con el objeto de estudio de la profesión.

- Potenciar la inteligencia de los estudiantes universitarios hacia la solución de problemas del diario acontecer. 
- Cualificar las habilidades comunicativas: leer, escribir, hablar, escuchar.

- Estimular la producción y creación.

- Dinamizar las formas de las clases.

- Posibilitar el trabajo individual y grupal.

- Educar para la vida.

Este documento presenta parte de los resultados de una investigación que pretende evaluar el cumplimiento de los objetivos y características de la estructura curricular vigente, iniciada en 2002. El enfoque es hermenéutico, lo que implica que la lectura de los elementos objeto de discusión convoque tres importantes atributos: el texto, el contexto y la propia percepción de los investigadores. Respecto de este último atributo, el interés primordial es subrayar aquellas situaciones o dinámicas que resultan problemáticas con el ánimo de encarar acciones que permitan cualificar la propuesta curricular.

La tentativa de comprender el sentido y las posibles intervenciones de un currículo problematizador es de gran interés por la dificultad para materializar este tipo de propuestas, ya sea por acoplamiento de las categorías básicas a los significados de currículos tradicionales (Barnett, 2001) o por el posible fracaso de una educación contable más liberal comprometida con el pensamiento crítico, la comprensión cultural, la habilidad comunicativa y la resolución de problemas (Stephen D. Willits, 2010, citado por Apostolou, Dorminey, Hassell \& Watson, 2013; León-Paime, 2013). La posibilidad de intervenir la propuesta curricular del programa de contaduría pública de la Universidad de Antioquia debe estar precedida por una evaluación de sus componentes, asunto nodal del presente documento.

El texto, luego de esta introducción, inicia con unas precisiones teóricas necesarias para tejer la matriz de sentido desde la que se habla, respecto de conceptos como pedagogía, currículo y didáctica. En el segundo apartado se caracterizan las declaraciones más importantes consignadas en los documentos base del programa de contaduría pública de la Universidad de Antioquia; esto en diálogo con conceptos y premisas de algunos autores expertos en la materia. Más adelante, en el acápite 3, se describe la metodología utilizada para la realización de esta investigación, que combinó la indagación directa a los estudiantes a través de la aplicación de encuestas y el análisis de los microcurrículos elaborados por los profesores y de sus prácticas en el aula. Finalmente, en el numeral 4 se recorren los análisis y las interpretaciones de la información recolectada, siempre intentando acompañar estos análisis de elementos conceptuales. Por último, se esbozan unas conclusiones que son más aperturas para mejorar el diagnóstico al que llega el presente trabajo.

\section{Pedagogía, currículo y didáctica. Aproximación nocional}

La teleología de los programas educativos es declarada en los documentos rectores, en los proyectos educativos de programa y en general, en los textos que son elaborados como guía del accionar de las comunidades que soportan el despliegue de una propuesta formativa. Los profesores, gestores y estudiantes deberían ce- 
ñirse a estos presupuestos para materializar los ideales curriculares, pedagógicos y didácticos que permiten sistemáticamente concretar lo proyectado. En este sentido, tales propuestas deben entregar suficientes pistas para que el camino de la acción educativa - como agencia de cada integrante de la comunidad educativasea comprensible.

Cuando se leen documentos rectores, proyectos de programa, motivaciones curriculares e informes de autoevaluación, entre otros, se identifican variadas narrativas muy cercanas a las discusiones de frontera en materia educativa con una teleología que resulta por lo menos sugerente. La idea de la formación integral, la construcción de pensamiento crítico, la conexión con necesidades reales de la sociedad y la apuesta por una profesión digna y dignificante son expresiones corrientes que dan cuenta de una apuesta contemporánea en materia de educación en oposición a las viejas escuelas tradicionales y conductistas.

La tensión aparece cuando nos preguntamos si esas entelequias curriculares, pedagógicas, didácticas (...) se concretan en prácticas cotidianas en los procesos de formación; es decir, si los documentos terminan siendo una guía efectiva para las prácticas que se desarrollan jornada tras jornada en los programas de contaduría pública del país. Hipotéticamente, podemos aventurarnos a señalar que hay una distancia marcada entre intencionalidad y práctica educativa, entre el sentido curricular y el currículo “cotidiano", entre pedagogía declarada y pedagogías presentes y entre didácticas recomendadas y metodologías de clase utilizadas en las aulas y por fuera de ellas. De esto dan cuenta los informes de acreditación institucionales en los que se sugiere una mayor coherencia entre los diseños curriculares y las prácticas de docencia, gestión, investigación y extensión.

Identificar los sentidos, lógicas y consecuencias de los modelos pedagógicos, las estrategias curriculares y las tendencias didácticas implica aguzar la mirada sobre las prácticas concretas, las formas y los modos especiales en que se materializa un currículo. Por supuesto, esto requiere tener muy claro el sentido de cada componente del sistema educativo, la intencionalidad que subyace a una propuesta específica y las maneras que debe asumir para concretarse coherentemente. En este marco de distinciones puede operarse una evaluación que permita mantener la esencialidad de un currículo como praxis $^{1}$.

Desde este presupuesto, la distancia entre teleología y cotidianidad del currículo, sigue un proceso de evaluación curricular que busca establecer el grado de coherencia entre las prácticas concretas y los sentidos que las soportan. También en alguna medida el identificar si el sentido primigenio de la propuesta educativa sigue siendo pertinente, ya sea en diálogo con una nueva frontera de conocimiento, o porque la misma práctica va mostrando la inoperancia u obsolescencia de ciertos enunciados. La tarea es entonces desentrañar cuáles son esos sentidos (tanto los teóricos como los prácticos) para poder comprender lo que pasa y proponer acciones que acerquen eso que pasa a la intencionalidad

\footnotetext{
1 Esta es la diferencia entre la práctica y la praxis, y debido al argumento anterior, la escuela debería estar centrada en la praxis y no en la práctica; es decir, una práctica reflexionada (De Zubiría, 2006, p. 62).
} 
declarada, o la intencionalidad a lo cotidiano. Como plantea Julián de Zubiría, asunto que aplica al mundo de la educación superior:

el cuaderno de un niño, los textos que usamos, un tablero con anotaciones, los contenidos que abordamos, la forma de disponer el salón o simplemente los términos utilizados para definir nuestras intenciones educativas, nos dicen mucho más de los modelos pedagógicos de lo que aparentemente podría pensarse (2006, p. 25).

Como lo expresa Rafael Flórez-Ochoa (1994), el divorcio que se puede encontrar entre teoría y práctica puede ser un síntoma de la ausencia de una teoría pedagógica. En términos simples, lo pedagógico actúa como un marco en el que se responden las preguntas más esenciales: ¿qué tipo de hombre y de sociedad merecemos o deseamos? ¿Qué teorías nos permiten comprender mejor ese tipo de hombre y esa sociedad? ¿Qué tradiciones deben mantenerse como cultura para equipar a los ciudadanos del mañana? ¿Qué debe ocurrir en términos educativos para formar un hombre con esas características para esa sociedad proyectada? Responder estas preguntas no es un asunto menor pues constituye la médula de la intencionalidad y la teleología de un proyecto educativo. Tal como subraya Julián de Zubiría: “toda teoría pedagógica es una teoría política. (...) Los modelos pedagógicos le asignan, así, funciones distintas a la educación porque parten de concepciones diferentes del ser humano y del tipo de hombre y de sociedad que se quiere contribuir a formar" (2006, p. 41).
En este sentido, un modelo pedagógico es una particular forma de encarar las grandes preguntas y de construir arreglos conceptuales para instalar un punto de mira y de entendimiento y con ello direccionar la educación en uno u otro camino. Los modelos pedagógicos presuponen una idea de lo correcto, una mixtura de valores y principios, y una sentencia sobre las pragmáticas más asertivas para concretar el ideal concebido. El hecho de que en un momento histórico se haya propugnado por una nueva pedagogía ha obedecido a contradicciones, nuevas demandas o insuficiencias, de ese sentido de la verdad, de los valores sociales promovidos o de las prácticas y metodologías seguidas para desarrollar los procesos educativos. Una transformación debe entonces expresar los peros de las antiguas formas de lo pedagógico y señalar las bondades del nuevo modelo pretendido. Lo que está en juego es un tipo de hombre y un tipo de sociedad.

En segunda instancia, aparece lo curricular que obedece a la estructuración y señalización de los elementos y las relaciones que concretan un proyecto educativo. Lo curricular reviste complejidad como sistema que debe acoplarse a un contexto limitado y promover un conjunto de propósitos que se definen en un marco de tensiones entre la sociedad y la propia universidad. Estructurar requiere mucho diálogo, lucidez y reflexión para encauzar y concretar la teleología de los programas.

Abraham Magendzo-Kolstrein (1991, p. 7) entiende el currículo como un camino o un trayecto propuesto por la institución educativa para transitar en la educación y formación de los estudiantes, el cual obedece a la idea que se tiene del hombre que se quiere formar. Según 
César Coll, citado por Julián de Zubiría (2006), el currículo se define por la resolución de estas preguntas: ¿Qué enseñar? ¿Cuándo enseñar? ¿Cómo enseñar? ¿Qué, cuándo y cómo evaluar?

Esto nos da una pista de la enunciación de Ronald Barnett (2001): un currículo comporta una epistemología, y en este sentido, se define como un proyecto epistemológico. $\mathrm{Al}$ responder las preguntas enunciadas, se elige una ruta de comprensión de la realidad y de lo educativo que actuará como esquema a priori para gatillar la acción. "Un currículo es pues la caracterización de los propósitos, los contenidos, la secuenciación, el método y la evaluación. Cada uno de estos elementos resuelve una pregunta pedagógica diferente pero interrelacionada" (De Zubiría, 2006, p. 40).

Tanto el modelo pedagógico como el curricular se concretan en el proyecto educativo. Un proyecto educativo es una prospectiva, la urdimbre conceptual que clarifica el sentido, un documento que expresa el conjunto de significantes que sustentan un programa curricular. En ese documento queda tangible el horizonte semántico que fundamenta la propuesta curricular y por lo tanto, la cartografía de lo que debe ocurrirle a un estudiante ${ }^{2}$.

Finalmente, la didáctica es ese subsistema que está comprometido más concretamente con el proceso de enseñanza-aprendizaje. Entendemos la didáctica como mediación, como práctica comunicativa, como interacción, pero interacción efectiva. Es la didáctica la que va a permitir concretar el modelo pedagógico en el

2 Una ampliación de los alcances de un proyecto educativo en contaduría pública ha sido trabajada por los profesores William Rojas y Carlos Ospina (Rojas \& Ospina, 2011). aula; este componente es el que permite la reconceptualización y recontextualización del conocimiento científico por parte de los estudiantes. La didáctica representa el proceso de mediación entre sujetos que se comunican haciendo, y es la transposición de las ciencias hacia su enseñanza mediante preguntas que permiten pensar, construir y solucionar problemas; por ello, promueve el proceso dialógico entre la enseñanza y el aprendizaje mediante la comunicación. La didáctica "es el espacio que se le brinda al estudiante para interrogar e interrogarse, cuando el maestro les va preguntando a sus discípulos aquello que quiere que aprendan" (Immanuel Kant, citado por González, 2001, p. 51).

La didáctica establece una relación profundamente dialéctica y recursiva con el currículo y la pedagogía. Se pregunta por las metodologías y las prácticas que permiten concretar el sentido pedagógico en un contexto determinado. Por ello, no es el conjunto de medios que se utilizan para apoyar la clase, sino un proceso de mayor calado que dispone de los mecanismos y las rutas para hacer efectiva la comunicación y la consolidación del proceso de conocimiento. Se mueve desde la elección de contenidos comprensibles, pasando por la identificación de las metodologías de clase, la elección de medios acoplados a las condiciones del aula, y desarrollando procesos metadidácticos para evaluar el nivel de logro y asertividad de las prácticas utilizadas. El problema de una mejor didáctica no se resuelve generando alternativas al magistrocentrismo, porque desafortunadamente hemos confundido, como lo expresa Julián de Zubiría (2006), el tipo de aprendizaje con el método de enseñanza. La didáctica trata de comprender cómo aprende el 
que aprende para poder proponer una dinámica que favorezca ese proceso de aprendizaje. No basta con variar las metodologías de clase sin una reflexión sobre los contenidos concretos, la secuencialidad de estos contenidos, el lenguaje de interacción más próximo al estudiante, los referentes psicocognitivos cruciales para fomentar una práctica de conocimiento específica, las condiciones contextuales y preformativas de los estudiantes, y en general todo aquello que vitaliza y potencia un adecuado proceso de comunicación e interacción.

Volviendo al inicio de este acápite, explicar la realidad pedagógica, curricular y didáctica de un programa implica el reconocimiento de la intencionalidad en los documentos que así lo expresan y requiere una observancia de las prácticas concretas y cotidianas que ejercen los integrantes de una comunidad educativa. Por supuesto, también se debe tener meridianamente claro que es eso de un currículo, una pedagogía y una didáctica. A veces, los entrecruces entre estos conceptos pueden confundirnos un poco, para lo cual nos queda el dialogar sistemáticamente hasta que las distinciones logren afectar nuestras comprensiones $y$, por ende, nuestras prácticas.

\section{El escenario de la transformación curricular del programa de contaduría pública de la Universidad de Antioquia}

\section{a) Las declaraciones}

Hacia finales de la década de los noventa y en un ambiente universitario (Universidad de An- tioquia) de apoyo a los procesos de transformación curricular, el programa de contaduría pública inició un trabajo sistemático de estudio, diálogo y decisión que dio como resultado una nueva propuesta curricular implementada a partir del primer semestre de 2002. Un análisis de más de diez programas de contaduría pública respecto al diseño curricular y la configuración del plan de estudios (Rueda-Delgado, 2009) 3 permite inferir que la propuesta del programa de contaduría pública reviste un matiz de originalidad en cuanto a su estructura por incorporar categorías de diseño como unidades de organización curricular, proyectos de aula, núcleos problémicos y el hecho de que varios proyectos de aula vinculan diversas disciplinas $y$, por ende, varios profesores en interacción ${ }^{4}$.

La autoevaluación del programa había identificado un conjunto de debilidades de las que mencionamos:

- La rigidez del plan de estudios.

- El poco desarrollo de habilidades para hablar en público, escribir e investigar.

- La utilización de la clase magistral casi como la única metodología del programa.

3 También se participó de un panel de análisis de estos programas en el IV Encuentro Nacional de Profesores de Contaduría Pública, celebrado en la Universidad de Antioquia y la Universidad EAFIT, en marzo de 2015.

4 No se profundizará acá sobre las características de este modelo, aparte de las que son necesarias para la exposición del problema que nos convoca. Una revisión en detalle del modelo curricular puede hacerse siguiendo la pista del documento de transformación curricular (Departamento de Ciencias Contables, 2000), del libro Recreando el currículo: contaduría pública (Carvalho-Betancur, Cadavid-Arango, Zapata, Tobón-Echeverri \& Duque-Roldan, 2006) y del texto Enfoque y estructura curricular: Convenio de cooperación académica entre programas de contaduría pública, en el capítulo relativo a la Universidad de Antioquia (Carvalho \& Ospina, 2009). 
- La falta de trabajo interdisciplinario.

- La poca discusión a problemas de contexto en el programa.

- La inexistencia de un núcleo de investigadores.

Y también identificó unos enunciados diagnósticos, entre los cuales se destacan:

- Desarticulación entre las asignaturas del mismo nivel.

- Falta armonización en el campo epistemológico propio de las ciencias contables.

- No se vislumbró relación alguna entre conceptos y su respectiva formación en valores y desarrollo de habilidades de pensamiento y de procesos creativos.

- Ausencia de un eje transversal que identifique la disciplina contable en el plan de estudios.

Estos elementos aunados a un auge de la discusión sobre el sentido mecánico de la educación, el verticalismo en el proceso de enseñanza (profesor-alumno), la poca preocupación por la formación en asuntos socioafectivos, la falta de integralidad, flexibilidad y pertinencia curricular, el reducido papel del estudiante en su proceso de formación, entre otras más ${ }^{5}$, permiten instalar una perspectiva para el programa

5 No se puede negar el importante papel jugado por la asesora de la transformación curricular, experta en educación, y quien sintonizaba con propuestas relacionadas con modelos curriculares alternativos al tradicional, en especial al currículo problematizador y a modelos pedagógicos desarrollistas y sociales. Su condición de experta favorecía el que profesores, egresados y estudiantes integrantes del grupo de trabajo para la transformación curricular llegáramos fácilmente a consensos respecto de estas alternativas curriculares. de contaduría pública con importantes tópicos y alcances y con una teleología muy prometedora.

La intencionalidad de la propuesta curricular puede ser dimensionada desde narrativas del siguiente estilo:

\begin{abstract}
La universidad necesita ser impulsada por
la transformación curricular de los distintos programas que componen su sistema educativo, con el objetivo de consolidar el papel reflexivo, crítico y propositivo de los profesionales que deberán poseer una dimensión política, ética y estética, de su actuar en la comunidad. La solución de problemas propios de su campo cognoscitivo y de orden social, bajo parámetros humanísticos, científicos y de desarrollo han de ser una cualidad fundamental del profesional que se requiere no solo en la Contaduría, sino en la generalidad de las profesiones (Departamento de Ciencias Contables, 2000, p. 13).
\end{abstract}

O relativas al sentido de la formación en tópicos tan importantes como la lógica de las ciencias, lo ético y lo estético:
Ahora bien, formarse es el proceso de cons- truirse, a sí mismo, una imagen mediadora a través de la relación del individuo, no solo con las cosas, sino con los otros, esos otros y esas cosas que también poseen su propia imagen. Es un problema de la ética en tanto se hace referencia al valor de lo humano en el obrar. Es un problema de lógica en tanto se hace referencia al desarrollo de habilida- des de pensamiento para satisfacer las ne- 
cesidades que esas cosas y esos individuos generan al vivir en sociedad, es la resolución de problemas. Y es un problema de estética en tanto hace referencia al efecto que las cosas y los otros tienen en cada individuo. Es la sensibilidad que despierta en la construcción de la imagen de esa persona (Departamento de Ciencias Contables, 2001, pp. 16-17).

Con mayor nitidez es apreciable el sentido de la "nueva" propuesta, en la definición de un conjunto de principios pedagógicos y didácticos (tabla 1) que se convertirían en la guía de las prácticas concretas del diseño curricular, de gestión, de evaluación, de dinámicas del proceso de enseñanza-aprendizaje. Una lectura muy detenida de estos principios permite hacerse una idea del cambio necesario para que en el currículo “vivo", el cotidiano, se pudiera dar cuenta de una transformación de los procesos formativos en los estudiantes de contaduría pública de la Universidad de Antioquia; un asunto que irreductiblemente implica un giro en las formas de comprensión y acción del profesorado y de los estudiantes del programa.

\section{Pedagógicos (redactados en clave: lo que debe pasar con los estudiantes)}

Ser conscientes y autónomos de su proceso de formación permanente.

La construcción de su propia imagen con base en la imagen de la naturaleza y la sociedad.

La articulación del mundo objetivo con el mundo de la escuela en beneficio del mundo de la vida.

El desarrollo de facultades intelectuales desde sus propias convicciones para contribuir al progreso social.

La apropiación creativamente de la lógica de las ciencias.

La construcción y aplicación de los conocimientos con fundamentos éticos y políticos.

El desarrollo de la lógica y de la estética como objetivos creativos que atraviesan el proceso formativo.
Didácticos (redactados en clave: lo que deben tener claro los profesores)

Las situaciones problémicas tanto de las ciencias mismas como del contexto local y global.

La lógica de los procesos propios de la construcción de las ciencias.

Sistemas de comunicación del conocimiento que superen el concepto del profesor como centro portador de la información.

La puesta en acción del aprendizaje verbal significativo.

El desarrollo de capacidades creativas y comunicativas.

La asimilación de los conceptos, las habilidades y los valores de las ciencias desde procesos cognitivos que sean sensibles.

La incorporación de las nuevas tecnologías educativas.

La evaluación como un proceso de certificación social.

Tabla 1. Principios pedagógicos y didácticos - Propuesta de transformación curricular, contaduría pública, Universidad de Antioquia

Fuente: estos principios aparecen en Propuesta de transformación curricular del Departamento de Ciencias Contables (2001, pp. 11-12) 
Estos principios son opuestos a las formas más tradicionales de concepción y prácticas educativas. Implican un descentramiento del papel del profesor, un viraje en la comprensión de la pregunta ¿cómo aprende un estudiante?, una redefinición del sentido de la formación universitaria ya no solo para el trabajo sino también para la vida, un acercamiento a tópicos tan esenciales como la emocionalidad, la ética, la estética e, incluso, la política. Y este cambio no se opera en el vacío, puesto que en el terreno de la educación, de la teoría pedagógica y curricular se venían y siguen gestando discusiones profundas sobre este tipo de transformaciones y sus consecuencias. Una práctica que debe desarrollarse recurrentemente es la crítica en el sentido de mantener viva la reflexión sobre los presupuestos y las dinámicas cotidianas de los elementos que componen el sistema educativo.

\section{b. Noción de pedagogía, currículo} y didáctica que se configura en el programa de contaduría pública de la

\section{Universidad de Antioquia}

Se plantea entonces un currículo basado en la solución de problemas para la formación de contadores públicos de la Universidad de Antioquia. No debe confundirse esta denominación con lo que da en llamarse Aprendizaje Basado en Problemas (ABP). El ABP carga su sentido más en el terreno metodológico, si se quiere didáctico. Un currículo basado en la solución de problemas identifica los tópicos relevantes que permiten dotar al estudiante de herramientas simbólicas, valóricas y prácticas para enfrentar su entorno profesional y para vivir mejor (problemas de formación) y también identifica los segmentos de la cultura que es menester desarrollar en el terreno de las preguntas de qué enseñar y cuándo enseñarlo (problemas del conocimiento).

Este diseño curricular encuentra eco en las palabras de Ronald Barnett:

$$
\begin{aligned}
& \text { Un currículo construido de esta manera no } \\
& \text { es un conjunto pre-armado de información y } \\
& \text { metodología al cual el estudiante se encuentra } \\
& \text { sujeto, sino más bien un marco relativamente } \\
& \text { flexible en el que los estudiantes pueden desa- } \\
& \text { rrollarse y del cual finalmente despegarán por } \\
& \text { su cuenta. Una educación superior es un pro- } \\
& \text { ceso abierto y no una venta de productos pre- } \\
& \text { determinados (Barnett, 2001, p. 71). }
\end{aligned}
$$

$\mathrm{Al}$ centrar la atención en problemas y no en contenidos se dispone como tentativa el despliegue de otras potencialidades del sujeto; por ello, no se habla de "competencias" como concepto catalizador de los logros educativos en el

6 Esta es una discusión de dimensiones que superan el objeto de este trabajo. Pero vale aclarar que la no definición de competencias expresas en el diseño curricular, obedecía en principio, a una lectura crítica de ese concepto que terminó fincado más en el sentido del trabajo y de lo funcional. Es obvio que la universidad tiene una relación directa con el mundo del trabajo; pero como inquiere Ronald Barnett (2001): ¿podemos concebir una educación superior para la vida como algo diferente a una educación superior para el trabajo? (p. 48). Por ello, cierta terminología terminó volviéndose caduca para el sentido de la Universidad, y aparecieron otros conceptos (no gratuitamente) para demarcar el sentido de lo que debe asimilarse por el papel de la educación superior. Conceptos como comprensión, verdad, sabiduría y crítica son reemplazados por otros más técnicos e instrumentales como calidad, competencia, suficiencia y habilidad. Por ejemplo: "El concepto de competencia tiene qué ver con la eficacia, mientras que el de comprensión se relaciona con la verdad. (...) hoy la pregunta clave es ‘funciona?’ y no ‘’es verdad?’” (Barnett, 2001, p. 147). 
estudiante, sino que se plantean propósitos de formación más sintonizados con el mundo de la vida. El "problema"7 resulta ser más pertinente para promover una estructura de significación cercana a la solución de necesidades sociales, a los procesos de cognición autónomos, a la idea de que el conocimiento se construye y no se descubre. También provee oportunidades para avanzar en la actualización, la secuenciación y flexibilización del plan de estudios y para construir verdaderos espacios de interdisciplinariedad puesto que los problemas no se solucionan desde campos de conocimiento fragmentados.

Desde el punto de mira de lo pedagógico, es evidente que la propuesta del programa de contaduría pública de la Universidad de Antioquia se ubica en una concepción alternativa a las modalidades tradicionales. Los modelos pedagógicos tradicionales, conductistas, e incluso la llamada Escuela Nueva o Pedagogía Activa, se convierten en senderos superados por la crítica a sus postulados. Del proyecto ilustrado asu-

7 Y no estamos descontando la discusión que puede tener la utilización de este concepto. Si no se cuida la perspectiva crítica con la que se proyecta su sentido, se puede caer en un escenario funcional, pero arropado por retóricas que pueden sonar alternativas. Traemos de nuevo a Ronald Barnett (2001, p. 56): “Sin embargo todos estos términos, y especialmente la resolución de problemas, también pueden considerarse métodos que ayudan a incorporar a la educación superior el decisionismo, otro término propio de la teoría crítica. Estos métodos de enseñanza serían medios que alientan a los alumnos a la toma de decisiones sin obligarlos a tener en cuenta la base ética o ambiental (en sentido general) de las mismas. La resolución de problemas parece neutral en cuanto a los valores, pero como sucede con todos los enfoques educativos su práctica está colmada de valores. La resolución de problemas es, aunque también pueda ser otras cosas, una técnica de la sociedad industrial moderna: una respuesta pragmática a los problemas de la sociedad en general". mido educativamente como enciclopedismo y del proyecto de educación para el mercado y el trabajo, se ponen en cuestión atributos como la transmisión de conocimiento, el privilegio de la memoria en el estudiante, el diseño asignaturista, el papel del estudiante en forma pasiva (heteroestructuración), el privilegio de la capacitación sobre la formación y el automatismo, entre otros (González, 1999; Ospina, 2009). Del modelo pedagógico relativo a la Escuela Nueva, si bien logra centrar la atención en el estudiante, para privilegiar sus potencialidades (autoestructuración) (Not, 1979/2000) y subrayar la búsqueda de una educación para la felicidad (De Zubiría, 2006), se critica la minusvaloración del papel del profesor, el marcado énfasis en lo actitudinal, el descuido por las preguntas sobre la pertinencia y secuencialidad de los contenidos y la borrosidad del sentido político de la educación, entre otros aspectos.

El modelo pedagógico del programa ha sido denominado expresamente como "de los procesos conscientes" (ver sus principios en la tabla 1). Se sitúa en una especie de mixtura entre el modelo pedagógico desarrollista y el modelo pedagógico social (González, 1999; Ospina, 2009) ${ }^{8}$. Muchos de sus elementos también se relacionan con lo que otros autores clasifican como el modelo pedagógico constructivista y el modelo pedagógico dialogante (De Zubiría, 2006). Diversos atributos interrelacionados que actúan recursivamente generan la

8 Puede revisarse la primera parte del libro Sobre la evaluación de currículos en la educación superior, para ampliar esta caracterización de los modelos pedagógicos (González, Upegui, Duque \& Álvarez, 2009). 
trama de sentido endosable a esta perspectiva de hombre y de sociedad; entre ellos:

- El compromiso con la cultura.

- La problematización de la subjetividad.

- La aproximación a la categoría "mundo de la vida".

- El desarrollo de semas complejos como interpretación, comprensión, reflexión y crítica.

- La búsqueda de la verdad pero no en el sentido absolutista de infalibilidad ni tampoco en el extremo de la pura relatividad. Más bien, el desarrollo de una episteme científica y problematizadora capaz de la argumentación y de la dialéctica de puntos de vista9

- La centralidad de un proyecto que busca la autonomización y emancipación del estudiante.

- La pertinencia entendida como contacto con los problemas y las necesidades sociales tanto locales como globales.

- La relación profesor-estudiante como diálogo interestructurante. Se presenta un equilibrio fundamental entre los roles del profesor y los del estudiante.

- El compromiso con la transformación social que propenda por la inclusión, la igualdad y la dignidad.

- Una concepción del ejercicio profesoral como autoinvestigación que favorezca una

9 La misión más importante es llevar a los estudiantes a intuir y hacerse cargo de los fines propios de la vida académica. Estos fines implican que las verdades no se dan por sentadas y siempre pueden ser desafiadas. También implican que los puntos de vista de cada uno se configuran o se expresan, a partir de la posibilidad de respaldarlos con razones y evidencias y dan por sentado que siempre hay más cosas por decir y que los problemas se pueden abordar desde otras perspectivas (Barnett, 2001, p. 49). didaxis cada vez más asertiva, es decir, una didáctica que en sentido estricto mejore la comunicación (Hernández, 1996).

- Una selección rigurosa de contenidos en función de los problemas y propósitos de formación. Pero también una flexibilización de estos mismos en coherencia con la problematización y con el conocimiento de frontera.

Desde lo didáctico, el proyecto de aula se erige como el espacio-tiempo que permite darle cauce al diseño: es la unidad concreta que materializa el sentido curricular y pedagógico. Se diferencia de la tradicional "materia" o "asignatura", porque representa elementos de mayor amplitud y más complejos. Conceptualmente, el proyecto de aula requiere un esfuerzo adicional del profesor pues su práctica es fundamental en la locomoción del currículo; asuntos como la definición del problema de conocimiento, la proposición de metodologías y didácticas coherentes, la reflexión sobre la evaluación de aprendizajes, la configuración de un producto tangible que dé cuenta del trabajo del proyecto de aula y, justamente, el sentido de espacio inacabado (proyecto) - que demanda una capacidad para derivar en estado de alerta, según las características contextuales, las cualidades de los estudiantes y la efectividad de las estrategias puestas en marcha-corroboran la centralidad y dependencia de este componente, para cumplir la teleología educativa proyectada.

El "proyecto de aula" es la célula central de expresión del proceso formativo. Allí, se postula desde la definición de problemas de conocimiento y de productos, pasando por 
la definición de metodologías y estrategias didácticas, hasta la proposición de dinámicas de evaluación de aprendizajes formativas en oposición a evaluaciones sumativas. Las metodologías de clase se hacen más variadas y enriquecidas en función de los propósitos de formación. No basta con la clase magistral, pero tampoco basta con la lúdica, el juego, la conversación y el énfasis en lo visual o en lo actitudinal. Las metodologías de clase deben pensarse con mucha lucidez desde referentes comunicacionales, es decir, desde una comprensión de los ¿cómo aprende el estudiante? (un poco psicopedagogía) en tensión con los ¿cómo puedo enseñar esta problemática? (la didaxis específica). Una promoción de lo alternativo solo como oposición al magistrocentrismo puede ser profundamente nefasta, si se soslayan preguntas adicionales sobre las condiciones del estudiante, sus a priori conceptuales, el sentido de los contenidos y su secuencialidad, y el carácter profundamente dialéctico entre epistemología y metodología.

Lo que sigue permite avanzar en la discusión sobre el currículo del programa de contaduría pública de la Universidad de Antioquia, en cuanto a si lo ideal ha logrado concretarse a partir de las declaraciones de los profesores en sus microcurrículos y la percepción de los estudiantes de las prácticas educativas.

\section{Metodología}

Para evaluar la congruencia entre el modelo pedagógico y curricular definido por el programa de contaduría pública de la Universidad de Antioquia y lo didáctico (lo que pasa en el aula), es decir, en el desarrollo de los proyectos de aula, se diseñó una investigación en la cual se plantearon varias estrategias de recolección de información, entre ellas las siguientes:

Análisis de microcurrículos: se analizaron los microcurrículos de 34 de los 52 proyectos de aula (65\%) que conforman el plan de formación. Se excluyeron del análisis los proyectos de aula relacionados con matemáticas, economía y formación ciudadana, dado que ellos no son administrados por el Departamento de Ciencias Contables y la mayoría se ofrece en forma conjunta con otros Departamentos de la Facultad de Ciencias Económicas, lo que dificulta la aplicación de los principios pedagógicos, curriculares y didácticos formulados por el programa. Para cada microcurrículo, se evaluaron los siguientes aspectos listados en la tabla 2.

\section{Encuesta aplicada a los estudiantes sobre} el proyecto de aula: se aplicó a los estudiantes una encuesta que tenía como objetivo medir su percepción sobre cada uno de los elementos que integran el proyecto de aula. La encuesta incluía 53 preguntas cerradas que evaluaban aspectos generales y de organización del proyecto, como los problemas y preguntas planteados, los objetivos definidos, los contenidos incluidos, el lenguaje empleado por el profesor, las estrategias didácticas utilizadas, la bibliografía y los medios, los espacios en los cuales se desarrolla el proyecto de aula, el tamaño del grupo, la intensidad horaria, la metodología de evaluación utilizada, las competencias y valores que desarrolla el proyecto y la inclusión de la investigación como método en el aula. También se evaluaron aspectos relacionados con la gestión curricular que hace la dirección del programa. El trabajo de campo 
ELEMENTOS PARA DISCUSIÓN / M. DUQUE, C. OSPINA / 369

\begin{tabular}{|c|c|}
\hline Concepto & Descripción \\
\hline \multicolumn{2}{|r|}{ Planeación y organización del proyecto de aula } \\
\hline Número de profesores & $\begin{array}{l}\text { Este aspecto busca determinar si el proyecto de aula se desarrolla de manera interdisciplinaria o } \\
\text { es ofrecido por un solo profesor. }\end{array}$ \\
\hline Justificación & $\begin{array}{l}\text { Se evalúa si el proyecto de aula en su justificación plantea la solución de necesidades } \\
\text { profesionales, sociales y cotidianas. }\end{array}$ \\
\hline Tipo de proyecto & $\begin{array}{l}\text { Se evalúa si el proyecto aborda aspectos teóricos, si combina teoría y práctica o si se desarrolla } \\
\text { solo desde la práctica. }\end{array}$ \\
\hline \multicolumn{2}{|r|}{ Componentes del sistema didáctico } \\
\hline Problema & $\begin{array}{l}\text { Problematizar la formación da señales de currículos no tradicionales que están enfocados no } \\
\text { solo en la transmisión de los contenidos, sino en la transformación de estos en conocimientos } \\
\text { que los estudiantes pueden aplicar para resolver situaciones de la sociedad en la cual van a } \\
\text { desarrollar su ejercicio profesional. Se evalúa si el proyecto de aula plantea problemas tanto de } \\
\text { formación como de conocimientos específicos, y preguntas problematizadoras. }\end{array}$ \\
\hline $\begin{array}{l}\text { Objetivos, } \\
\text { competencias }\end{array}$ & $\begin{array}{l}\text { Permite identificar si se desarrolla un modelo tradicional, cuando los objetivos están centrados } \\
\text { en lo que el profesor realiza; o alternativo, cuando los objetivos están en función del aprendizaje } \\
\text { del estudiante o en el desarrollo de competencias científicas. }\end{array}$ \\
\hline Método & $\begin{array}{l}\text { El método describe el camino seguido en el aula para dar solución a los problemas y alcanzar los } \\
\text { objetivos, se evalúa si el método está centrado en el quehacer del profesor o en la construcción } \\
\text { que puedan desarrollar los estudiantes y en la comunicación permanente entre docente- } \\
\text { estudiante. }\end{array}$ \\
\hline Estrategias didácticas & $\begin{array}{l}\text { Las estrategias didácticas también dan señales del modelo pedagógico desarrollado, si están } \\
\text { centradas en la clase magistral estaríamos ante un modelo pedagógico tradicional pero } \\
\text { si se contemplan didácticas activas como el trabajo de campo, los clubes de revista o la } \\
\text { experimentación, darían señas de modelos alternativos. }\end{array}$ \\
\hline Medios & $\begin{array}{l}\text { Los medios empleados también señalan el modelo pedagógico instaurado: el tablero o la } \\
\text { utilización de diapositivas señalan clases tradicionales; las herramientas virtuales, aplicaciones } \\
\text { (software), simuladores y bases de datos, entre otros, señalarían la aparición de modelos } \\
\text { alternativos. }\end{array}$ \\
\hline Evaluación & $\begin{array}{l}\text { La evaluación sumativa (exámenes, quices, talleres, trabajos y exposiciones) se enmarcan en } \\
\text { modelos evaluativos tradicionales, mientras que la evaluación formativa (solución de casos } \\
\text { aplicados, la construcción de modelos, la preparación de estados del arte y de ponencias, entre } \\
\text { otros) se considera un método evaluativo de modelos alternativos. }\end{array}$ \\
\hline
\end{tabular}

Tabla 2. Aspectos evaluados del diseño de los microcurrículos de los proyectos de aula Fuente: elaboración propia

se realizó a finales del año 2014 y se aplicaron 1.357 encuestas para cubrir 36 proyectos de aula de los 52 que componen el plan de formación.

Encuesta aplicada a los estudiantes so-

bre las prácticas docentes: se aplicó un instrumento de 24 preguntas, que evaluaban aspectos como la planeación de las actividades desarrolladas en el aula, el lenguaje y las didácticas utilizadas, el trato del profesor hacia los estudiantes y el acompañamiento por fuera del aula, entre otros aspectos. El trabajo de campo se realizó a finales del año 2014 y se aplicaron 2.320 encuestas en 36 proyectos de aula, en las que se recogió información respecto de 62 profesores que participan en esos proyectos.

Proyectos de aula por semestre: para definir el número de proyectos de aula que se evaluarían por semestre se utilizó un muestreo no 
probabilístico por criterios o fines especiales en el cual se escogieron los miembros de la muestra, es decir, el investigador eligió el número y los elementos que la iban a conformar. Se utilizó esta estrategia dado que se querían excluir los proyec- tos de aula que no son administrados directamente por el Departamento de Ciencias Contables y en los cuales no se aplica el modelo curricular basado en la solución de problemas, como inglés, matemáticas y formación ciudadana.

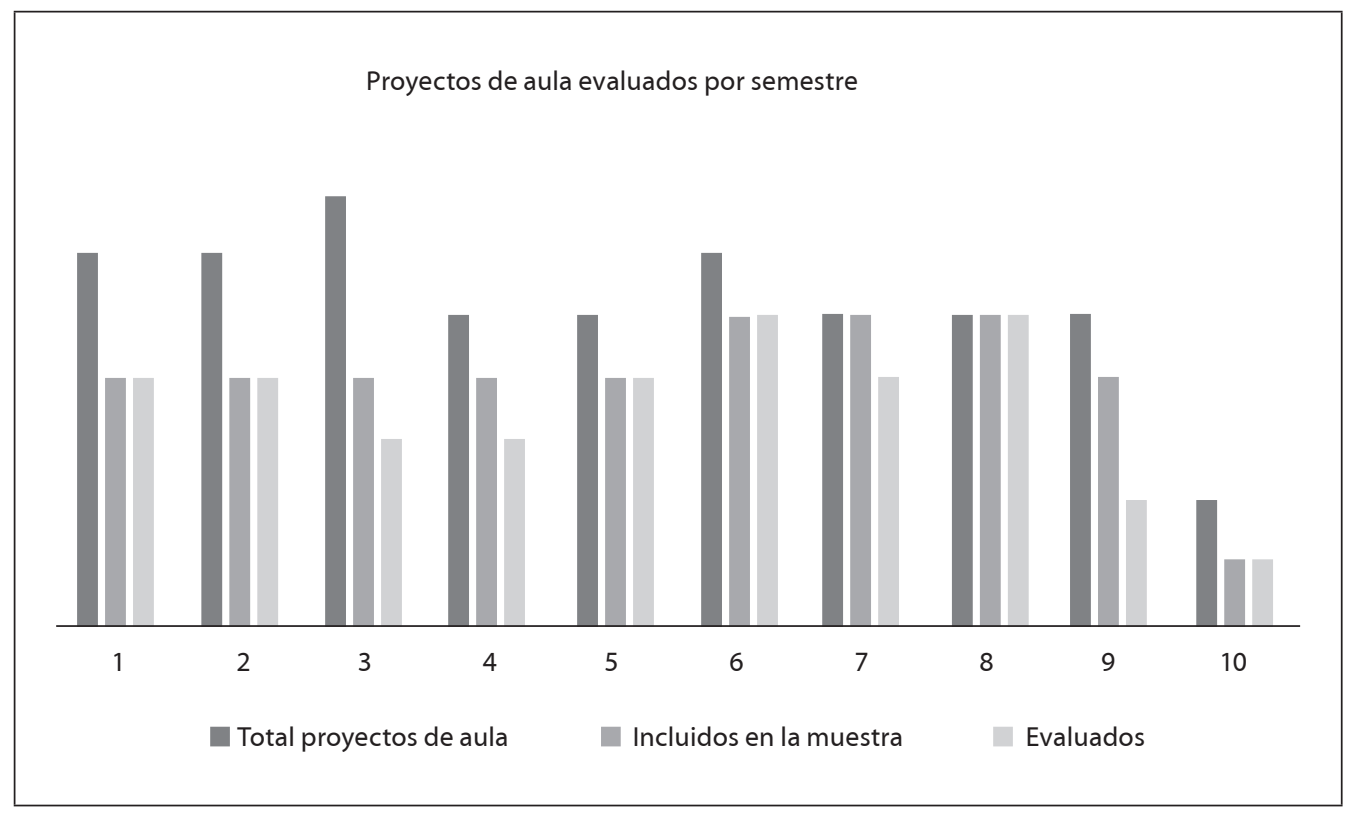

Gráfico 1. Proyectos de aula evaluados Fuente: elaboración propia

Por tanto, se determinó que del total de los proyectos de aula que hacen parte del programa de contaduría (52), se incluirían en el estudio 40. Sin embargo, por las dinámicas propias de cada curso no fue posible realizar la encuesta en 4 de ellos, razón por la cual efectivamente se evaluaron 36 proyectos que corresponden al $90 \%$, lo que se considera una muestra representativa de la población objeto de estudio.
Género del encuestado: el 57\% de los estudiantes encuestados corresponde a mujeres, el 34\% hombres y el 9\% restante no respondieron esta pregunta.

Tipo de estudiante: en promedio, el 55\% de los estudiantes encuestados se dedica solo a sus estudios, el 30\% está conformado por estudiantes-trabajadores y el 15\% no respondió esta pregunta. 
ELEMENTOS PARA DISCUSIÓN / M. DUQUE, C. OSPINA / 371

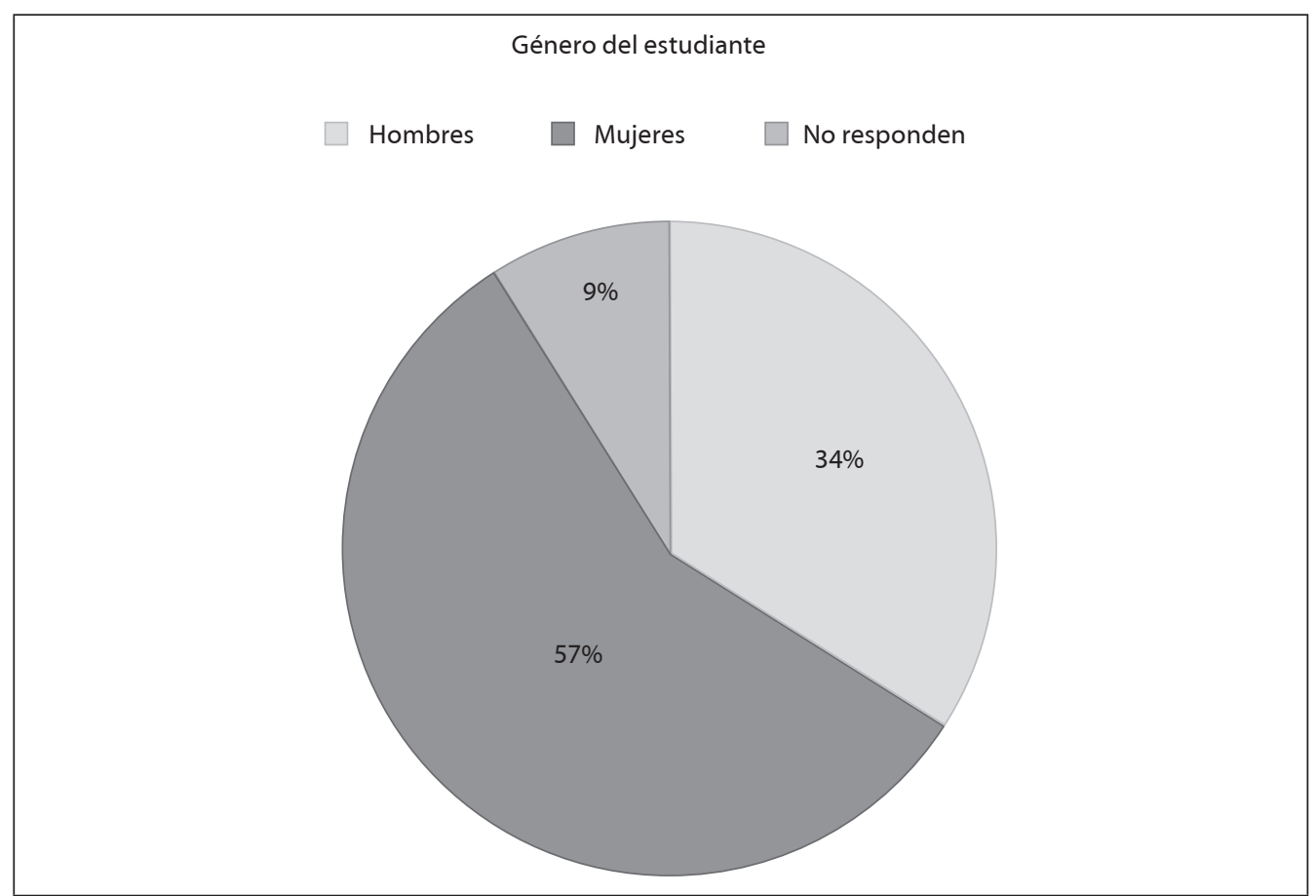

Gráfico 2. Género del estudiante encuestado

Fuente: elaboración propia

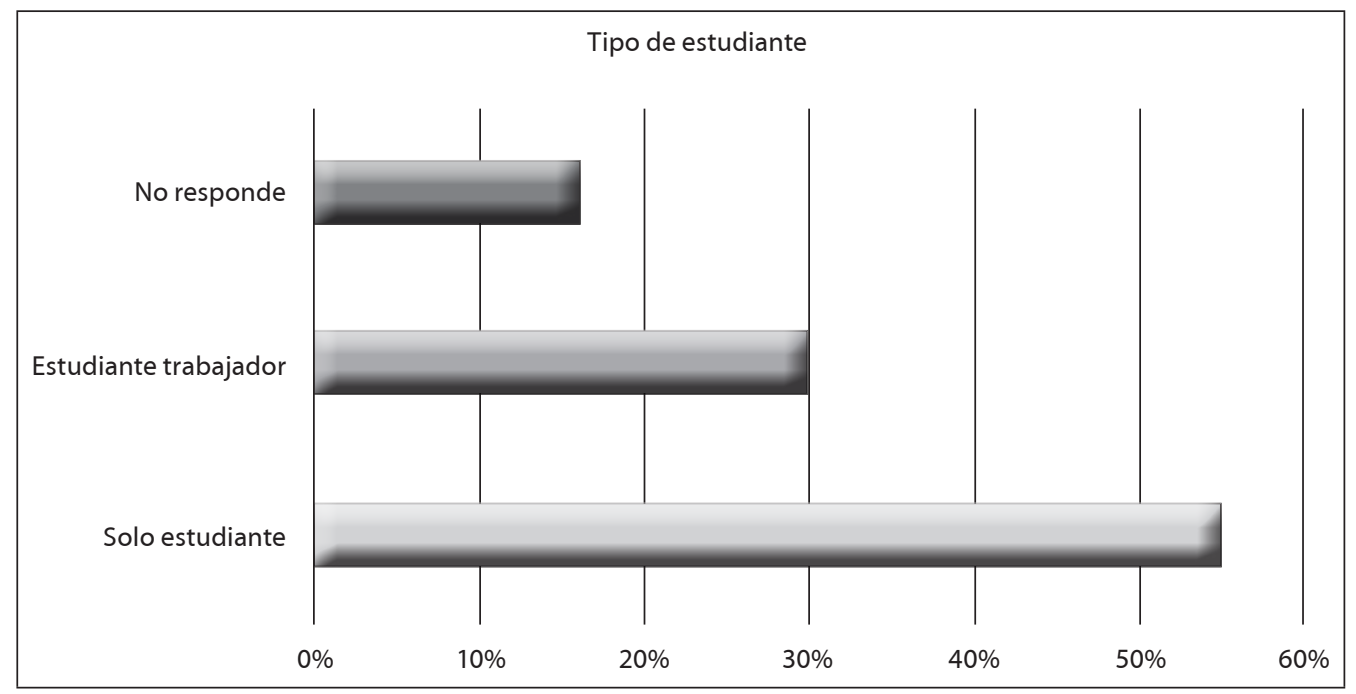

Gráfico 3. Tipo de estudiante encuestado

Fuente: elaboración propia 


\section{Algunos resultados}

A continuación, se presentan los principales resultados obtenidos en el trabajo de campo, que se dividirán para este análisis en 4 grupos; el primero detalla lo que tiene qué ver con la organización y planificación de los proyectos de aula; el segundo, con el sistema didáctico que soporta el desarrollo de los proyectos; en tercer lugar, se evalúan las prácticas docentes y por último, la gestión curricular.

\section{a. Organización y planificación de los proyectos de aula}

Este aspecto evalúa que los proyectos de aula cuenten con microcurrículos diseñados de acuerdo con las características del modelo seleccionado por el programa y de acuerdo con las directrices dadas para su construcción por el Departamento de Ciencias Contables (pueden consultarse en González-Agudelo, Upegui-Velásquez, Duque-Roldán \& Álvarez-Osorio, 2009, en la sección anexo 1), que estén disponibles para los estudiantes, que sean explicadas al comienzo del curso y que tengan una justificación que sustente la importancia de lo que en el proyecto de aula se va a trabajar y de las necesidades profesionales, sociales o cotidianas que permitirá resolver el conocimiento que los estudiantes desarrollarán. También analiza aspectos como el número de profesores que participan y si el proyecto de aula es teórico o práctico.

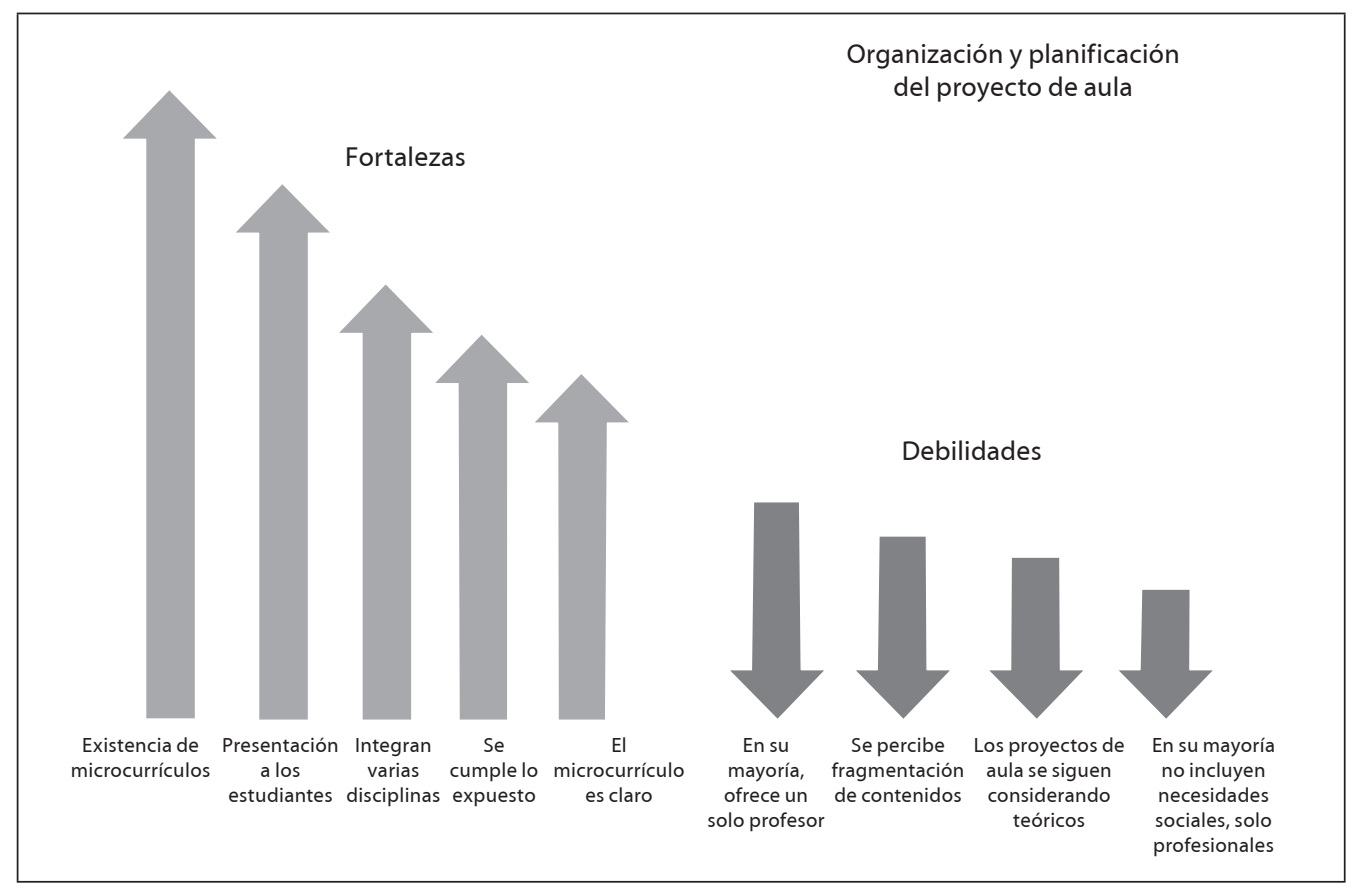

Gráfico 4. Debilidades y fortalezas de la organización y planificación del proyecto de aula Fuente: elaboración propia 
En el análisis realizado a los microcurrículos, se encontró que todos cumplen el diseño definido por el Departamento de Ciencias Contables, lo que resulta satisfactorio. El 91\% de los microcurrículos analizados construye una justificación que solo tiene en cuenta necesidades profesionales, mientras el $9 \%$ restante incluye en la descripción la importancia que tiene el proyecto de aula en la resolución de necesidades sociales y profesionales.

En cuanto al número de profesores que ofrecen el proyecto de aula, en el $67 \%$ de los proyectos hay un solo profesor, en el 25\% de los proyectos participan dos profesores y en el 8\% participan 3 o más profesores.

Según la información registrada en los microcurrículos, en el $62 \%$ de estos no se define si el proyecto de aula es teórico, teórico-práctico o práctico, el $26 \%$ especifican que son teóricoprácticos, el 9\% declaran ser teóricos y el 3\% totalmente prácticos.

En las encuestas aplicadas a los estudiantes, el 91\% sostiene que el profesor presenta el proyecto de aula y el cronograma de actividades el primer día de clase, pero solo el 73\% considera que lo expuesto se cumple y un $68 \%$ entiende claramente esa presentación. Aunque los porcentajes anteriormente descritos muestran que hay una planificación de lo que se va a realizar en el aula y esta se comparte con los estudiantes, se ve necesario mejorar los procesos de comunicación y de cumplimiento de lo expuesto el primer día de clase.

Para los estudiantes encuestados, el 63\% de los proyectos es teórico-práctico, el $27 \%$ considera que los proyectos son teóricos, el $8 \%$ cree que son prácticos y el $2 \%$ restante no responde. La diferencia que se presenta entre lo consignado en el microcurrículo y lo manifestado por los estudiantes puede estar justificada en que los estudiantes consideran un proyecto teórico-práctico cuando en él se plantean ejercicios que se resuelven en la clase y no porque necesariamente involucren un contacto con la realidad social o profesional que enfrentará el estudiante.

Para el 77\% de los estudiantes, los proyectos de aula integran varias disciplinas pero plantean observaciones frente a la falta de cohesión entre los diferentes profesores que participan en los proyectos de aula; se percibe fragmentación o división de los "contenidos" entre los profesores y falta de comunicación. Esto dificulta la superación de la situación de currículo agregado o asignaturista.

El hecho de que un porcentaje tan alto de proyectos de aula no incluya necesidades sociales o cotidianas a resolver puede ser un indicio de una orientación tradicional de la educación que forma solo para el empleo y no para la vida.

De acuerdo al modelo curricular definido para el programa de contaduría se esperaría que todos los proyectos de aula combinaran teoría y práctica, pero un porcentaje importante aún se percibe totalmente teórico, lo que también muestra una tendencia a enfoques tradicionales de formación.

\section{b. Sistema didáctico}

En un modelo curricular como el que se implementó en el programa de contaduría pública de la Universidad de Antioquia, la didáctica tiene una serie de componentes interrelacionados, que permiten conectar los conocimientos científicos que requieren ser aprehendidos por los estudiantes con la mejor forma de lograr su comprensión. 


\section{Componentes del sistema didáctico}

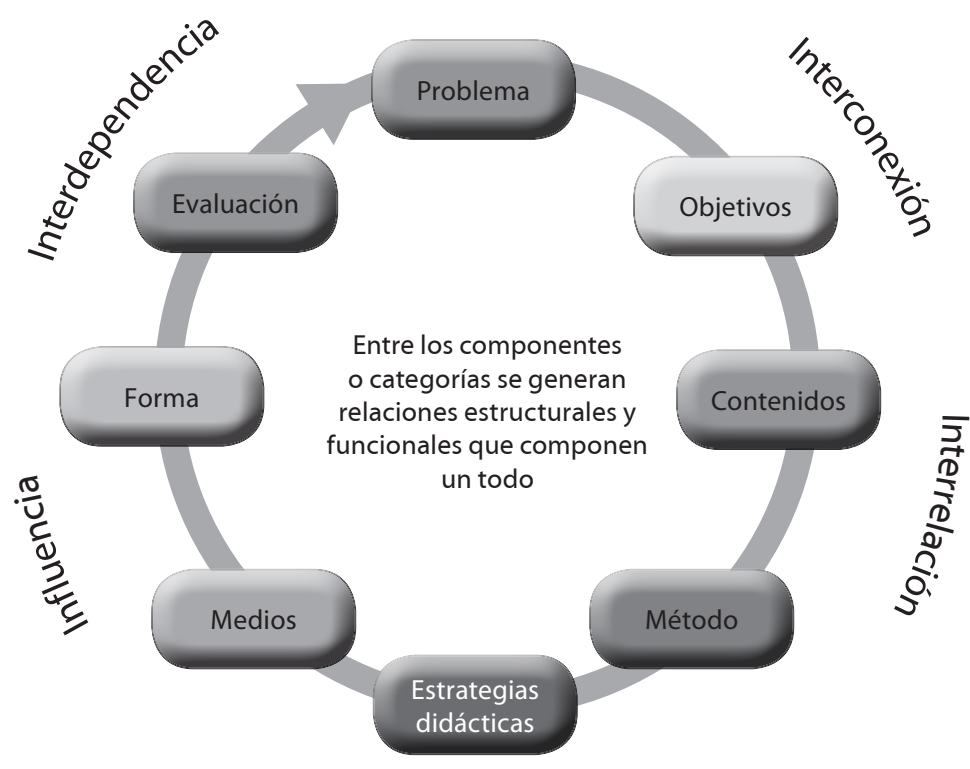

Causalidad circular

Gráfico 5. Componentes del sistema didáctico

Fuente: elaboración propia

A continuación, se evaluará cada uno de estos componentes:

\section{i. Problema}

Las situaciones problémicas son el punto de partida de todo el proceso didáctico. Como dice Paulo Freire (1970), citado por Jovany GómezVahos (2002), cuanto más se problematizan los educandos, como seres en el mundo y con el mundo, se sentirán mayormente desafiados, tanto más desafiados cuanto más obligados se ven a responder al desafío, por ello deben plantearse problemas y preguntas contextualizados a la realidad social, económica y cultural de los educandos, que movilicen su pensamiento hacia la solución. Según Jovany Gómez-Vahos:

La pedagogía que problematiza no puede fundamentarse en una comprensión de los hombres como seres vacíos a los que el mundo "llena" de contenidos ni en una conciencia mecánica, sino una conciencia intencionada al mundo, que está dispuesta a descubrirlo, crearlo y recrearlo (2002, p. 30).

María Victoria Alzate, Miguel Ángel Gómez y Martha Cecilia Arbeláez (2011, pp. 
85-86) plantean que hay diferentes tipos de problematizaciones y no todas conducen al desarrollo de competencias científicas en el estudiante:

- Activa: se plantea el problema y se solicita la respuesta por parte de los estudiantes.

- Alusiva: se plantea el problema y se invita a los estudiantes a reflexionar sobre él.

- Falsa/activa: se plantea el problema pero el profesor da la respuesta. Normalmente, se da cuando las condiciones del proceso no son aptas para que el estudiante solucione el problema.
- Relato de problemas: se describen problemas que se plantean en la práctica profesional y el profesor indica las posibles soluciones.

Según María Victoria Alzate, Miguel Ángel Gómez y Martha Cecilia Arbeláez, solo la problematización activa se considera una auténtica problematización, porque le permite al estudiante de manera autónoma acercarse al conocimiento que le va a permitir resolverlo.

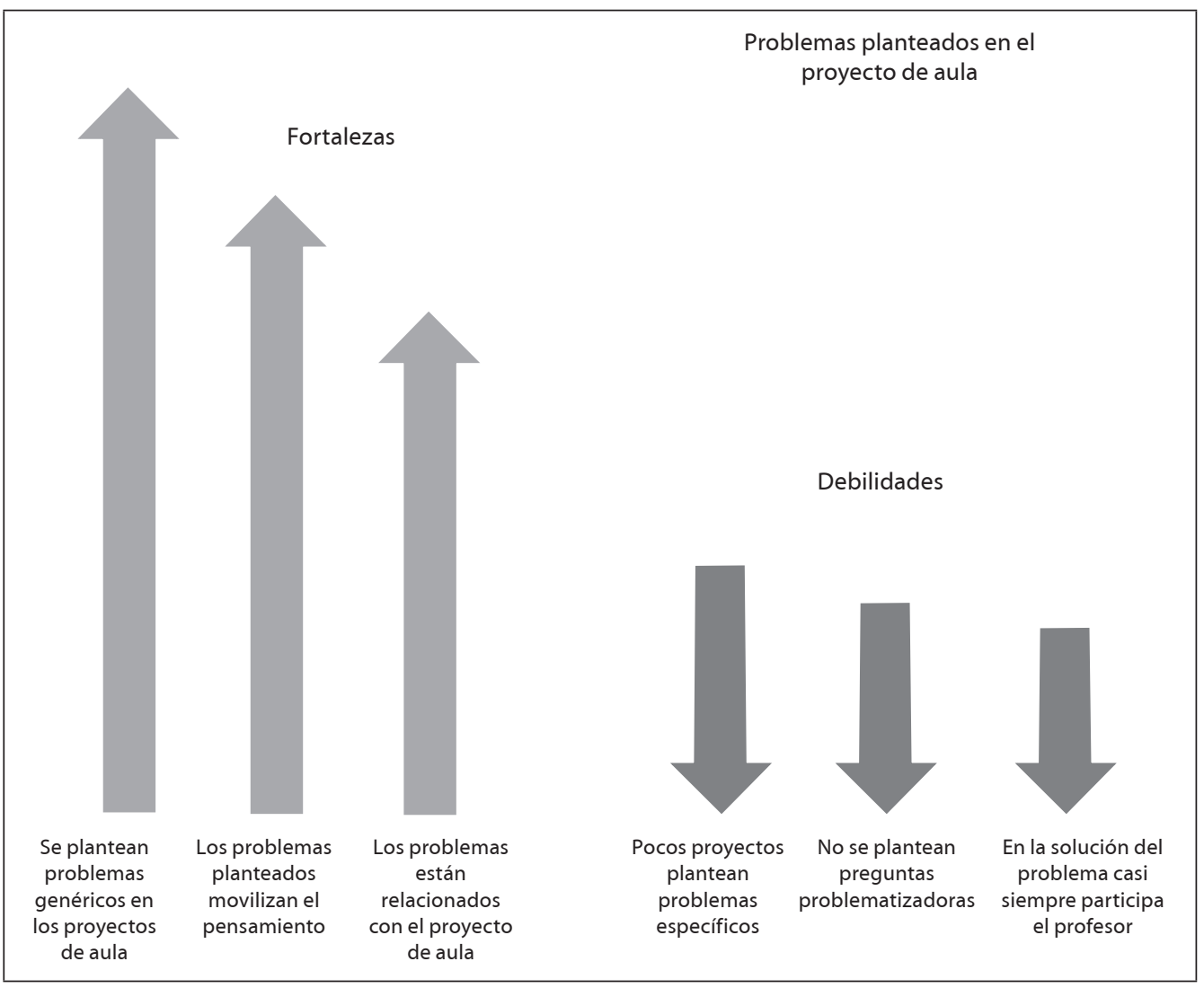

Gráfico 6. Debilidades y fortalezas en la formulación de problemas Fuente: elaboración propia 
En el análisis realizado a los microcurrículos del programa de contaduría pública se pudo constatar que el 77\% de los microcurrículos estudiados plantea los problemas de formación predefinidos en la reforma curricular del programa, mientras que el 23\% restante plantea problemas de formación propios de cada proyecto de aula. En muy pocos microcurrículos se formulan preguntas problematizadoras. Esto permite deducir que los profesores aún no se familiarizan con el proceso de formulación de problemas y preguntas específicas de sus proyectos de aula que movilicen la reflexión de los estudiantes; o si las plantean en el desarrollo del curso, no queda evidencia de ello en el microcurrículo.

Al preguntar a los estudiantes por los problemas definidos en los microcurrículos, el $70 \%$ de ellos considera que los problemas definidos movilizan su pensamiento hacia la solución y que estos problemas están relacionados con el proyecto de aula. Estos problemas son resueltos según los estudiantes en su mayoría (59\%) entre estudiantes y profesores, el 34\% considera que los resuelve el profesor y solo un $4 \%$ de los estudiantes considera que ellos mismos resuelven las preguntas y problemas formulados en los proyectos de aula.

Por lo tanto, si se tiene en cuenta que el objetivo del modelo curricular del programa es formular problemas y preguntas que movilicen el pensamiento del estudiante para que él mismo los resuelva de manera autónoma, reflexiva y analítica, que les permita avanzar en los procesos de pensamiento reflexivo y propositivo, esto no se estaría logrando aún y el profesor si- gue teniendo un papel protagónico no solo en el planteamiento, sino en la solución de los problemas. Esto estaría más cercano a modelos curriculares y pedagógicos tradicionales.

\section{ii. Objetivos, competencias}

A partir de los problemas planteados se definen los objetivos, entendidos según Carlos M. Álvarez de Zayas y Elvia María GonzálezAgudelo (2002, p. 44) como la aspiración, el propósito que se quiere formar en los estudiantes. Estos objetivos se dirigen a la formación integral de los estudiantes, desde lo instructivo, lo educativo y lo desarrollador, y deben tener en cuenta todas las facetas de la personalidad (Quiroz-Posada \& Monsalve-Díaz, 2004, p. 110). Es muy importante que los objetivos planteados en cada uno de los espacios formativos se encuentren redactados en función del aprendizaje del estudiante y no en términos de lo que el profesor espera lograr mediante la enseñanza. Si los objetivos son redactados en términos de competencias ${ }^{10}$, estas competencias deben ser científicas para que integren el pensamiento y la acción y permitan la comprensión, no solo el desempeño laboral.

10 Ya habíamos indicado antes que en principio no se habían definido competencias por una distancia crítica frente al término. Si bien la política educativa actual subraya e insiste en el uso del concepto de competencia, el programa se ha insertado en el diseño microcurricular cuidando que el enfoque no sea eminentemente instrumental y funcional. 


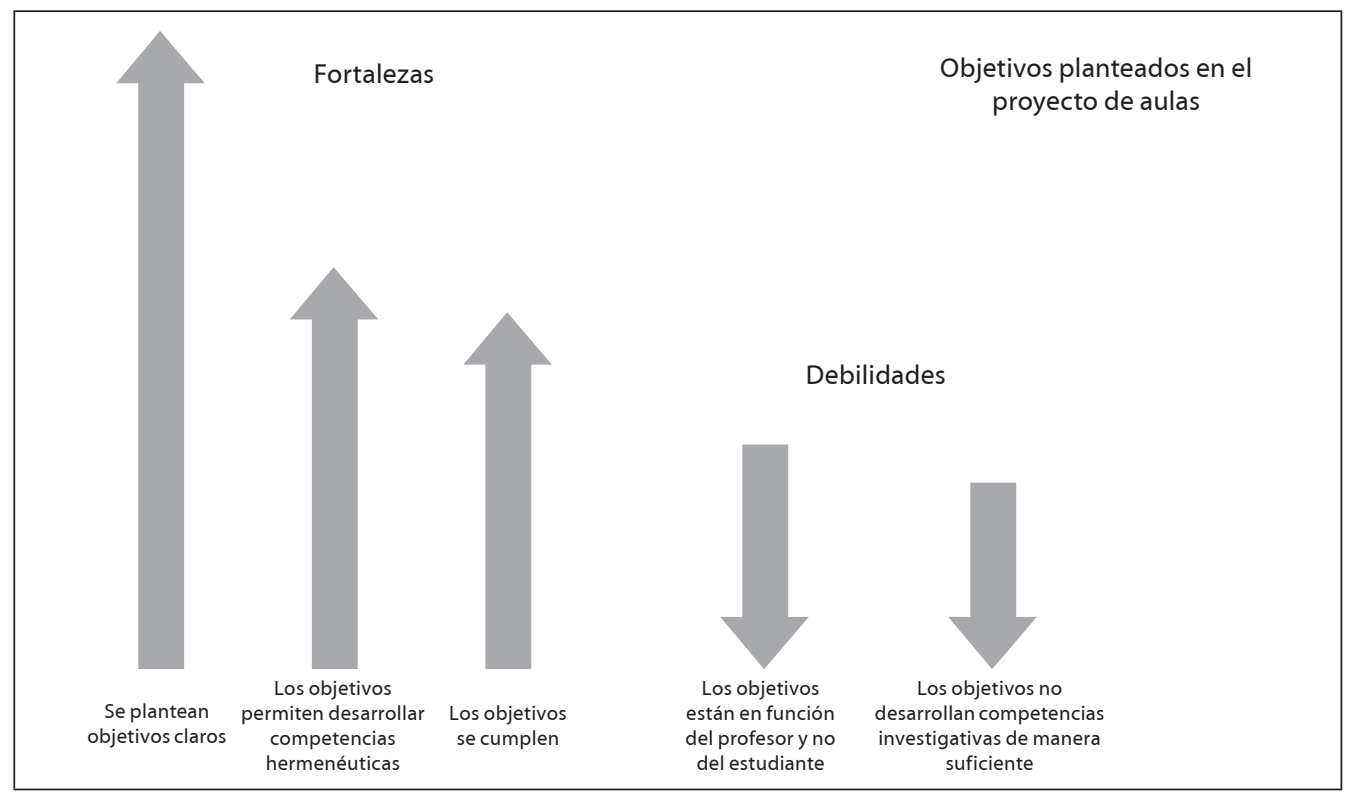

Gráfico 7. Debilidades y fortalezas en los objetivos de los proyectos de aula Fuente: elaboración propia

En el análisis de los microcurrículos, se pudo detectar que en el 65\% de estos, los objetivos están en función del profesor (fomentar, desarrollar, formar, brindar al estudiante, trabajar e incentivar, entre otros) y solo el 35\% plantea objetivos centrados en el estudiante (comprender, proponer, modelar y construir, entre otros).

Todos los proyectos de aula definen competencias, el 8\% de ellas está entre las consideradas dialécticas (comunicar, argumentar, sintetizar), el 72\% de las competencias definidas está entre las hermenéuticas (analizar, comparar, comprender, interpretar) y solo el $20 \%$ se considera investigativas (formular preguntas y/o problemas, seleccionar alternativas de solución; manejar bases de datos especializadas; interpretar información científica, construir estados del arte o modelos contables, marcos teóricos y artículos, entre otros), las cuales se incluyen solo en 8 proyectos de aula.

Para el 62\% de los estudiantes, los objetivos de los proyectos de aula son claros y el 59\% considera que se cumplen. En cuanto a las competencias, su visión es diferente a lo planteado en los microcurrículos pues consideran que las competencias investigativas son las que más se desarrollan con un $46 \%$ (indagar, formular preguntas, proponer, manejar bases de datos, confrontar teorías, construir estados del arte y utilizar TIC), seguidas de las competencias dialécticas con un 34\% (escuchar, argumentar, dialogar, tolerar) y, por último, las competencias hermenéuticas con un 20\% (comprender, sintetizar).

El hecho de que solo un poco más el 50\% de los estudiantes manifieste que los objetivos se cumplen y que estos objetivos en su mayoría 
estén en función del profesor da señales de que los principios planteados en el modelo curricular no se están cumpliendo; adicionalmente, puede haber una confusión en el concepto de competencia que se desarrolla en el aula pues los resultados son contradictorios entre lo que se plantea en el microcurrículo y lo que perciben los estudiantes.

\section{iii. Contenidos}

Los contenidos ofrecen la información necesaria para la solución del problema, el cumplimiento de los objetivos y el desarrollo de las competencias. De acuerdo con Miguel Ángel Zabalza: la formación universitaria ha de ser por su propia naturaleza, una formación de alto nivel y que deje bien sentadas las bases para los aprendizajes posteriores. Eso solo se logra con una adecuada selección de contenidos, escoger los más importantes, acomodarlos a las necesidades formativas, a los tiempos y recursos disponibles (...) La forma en que se ordenen los temas y las conexiones que se establezcan con otras disciplinas y con situaciones o problemas de la vida real servirá de orientación y modelo a la forma como los estudiantes construyen su aprendizaje (2007, p. 78).

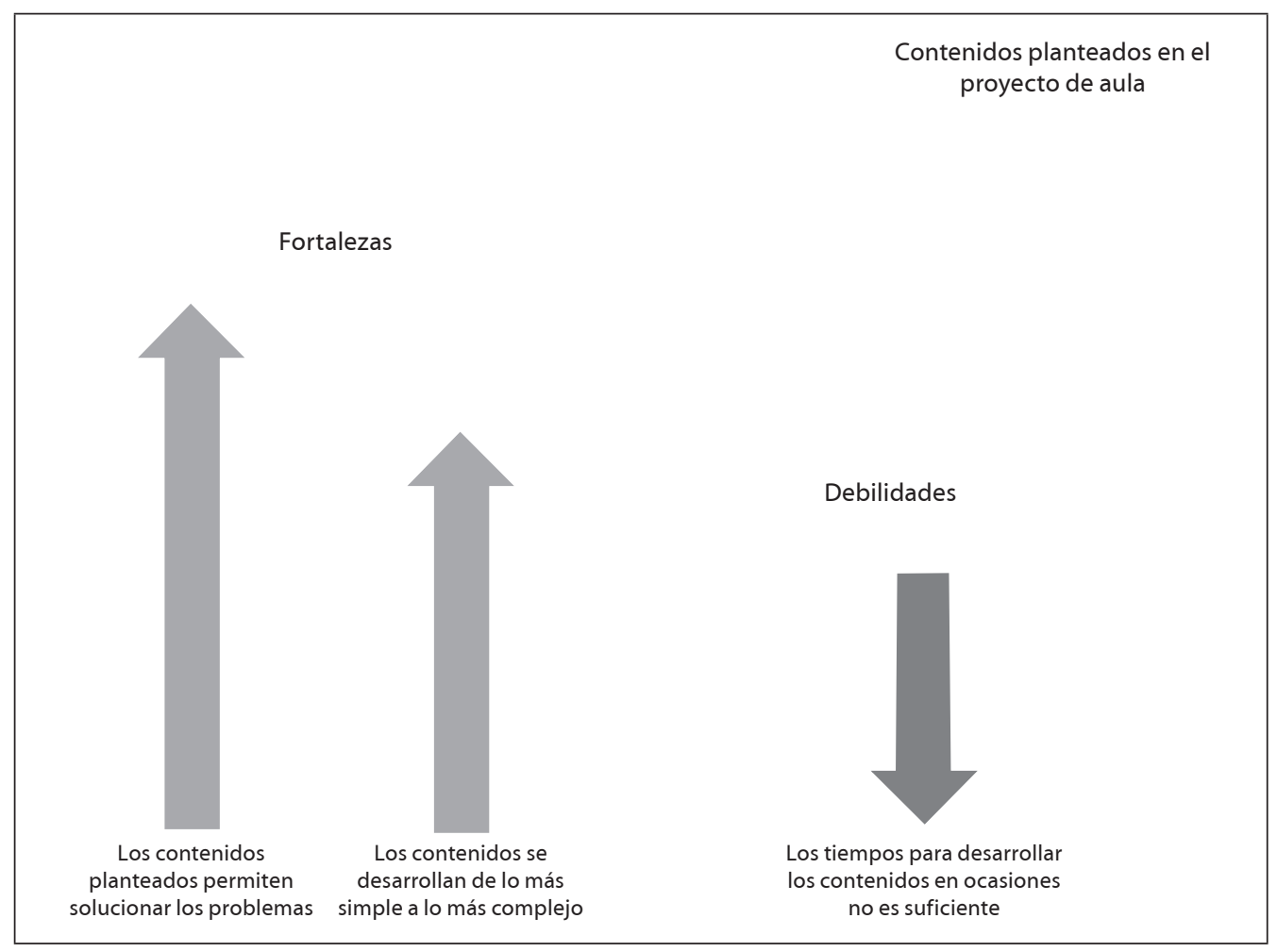

Gráfico 8. Debilidades y fortalezas en los contenidos desarrollados en los proyectos de aula Fuente: elaboración propia 
En el análisis de los microcurrículos, se detectó que todos presentan contenidos detallados pero no se evaluó su pertinencia para el cumplimiento de los objetivos y la solución de los problemas planteados. En todos los casos, es presumible que la elección de contenidos sea de competencia de los profesores y que falte un poco más de evaluación desde las instancias que monitorean el currículo.

El 77\% de los estudiantes que respondieron las encuestas considera que los contenidos planteados en los proyectos de aula permiten resolver los problemas y el $71 \%$ considera que se desarrollan de lo más simple a lo más complejo. En cuanto a los tiempos destinados a desarrollar los contenidos, el 57\% considera que se desarrollan en los tiempos planteados. Por las observaciones consignadas en el instrumento diligenciado por los estudiantes se puede deducir que en algunos proyectos de aula los contenidos desarrollados pueden ser demasiado para el tiempo disponible o pueden presentarse problemas en la distribución de los tiempos. Este punto resiste un análisis más riguroso para interpretar la pertinencia de los contenidos y la forma de secuencialidad que reside en ellos.

\section{iv. Método}

El método es la planificación que se hace del proceso de enseñanza-aprendizaje para ayudar al estudiante a comprender los contenidos, cumplir los objetivos y resolver los problemas. De acuerdo con Carlos M. Álvarez de Zayas y Elvia María González-Agudelo:

\footnotetext{
Es la organización interna del proceso en tanto proceso de comunicación y actividad.
}

\begin{abstract}
Es la configuración que adopta, es un camino que construye el alumno para alcanzar su objetivo. El método es quien hace girar el sistema didáctico en círculos en espiral sin límites, en una red de relaciones que establece un entramado entre los componentes del sistema para transponer y mediatizar los conocimientos. El método no es solo una parte, sino que es el todo, que a la vez está en cada una de las partes (2002, p. 52).
\end{abstract}

Para Edgar Morin, Emilio Roger Ciurana y Raúl Domingo Motta, el método:

[...] es un discurso, un ensayo prolongado de un camino que se piensa. Es un viaje, un desafío, una travesía, una estrategia que se ensaya para llegar a un final pensado, imaginado y al mismo tiempo insólito, imprevisto y errante. No es el discurrir de un pensamiento seguro de sí mismo, es una búsqueda que se inventa y se reconstruye continuamente (2003, p. 15).

En el método, el estudiante entra en contacto con el contenido y se generan los espacios para la comunicación entre profesor y estudiante; entre los estudiantes; $y$ entre el contenido y el estudiante con el fin de posibilitar la comprensión del contenido, es decir, su conocimiento. El método es el que permite la construcción del conocimiento (González, s.f., p. 6). En los currículos problematizadores, el método es esencialmente dialógico. Para Paulo Freire:

\footnotetext{
[...] el diálogo fenomenaliza e historiza la esencial intersubjetividad humana: él es re-
} 
lacional y en él nadie tiene la iniciativa absoluta. Los dialogantes "admiran" un mismo mundo; de él se apartan y con él coinciden: en él se ponen y se oponen. Vemos que, de este modo la conciencia adquiere existencia. La verdadera educación se da en la relación interpersonal, en el diálogo (2005, p. 12).

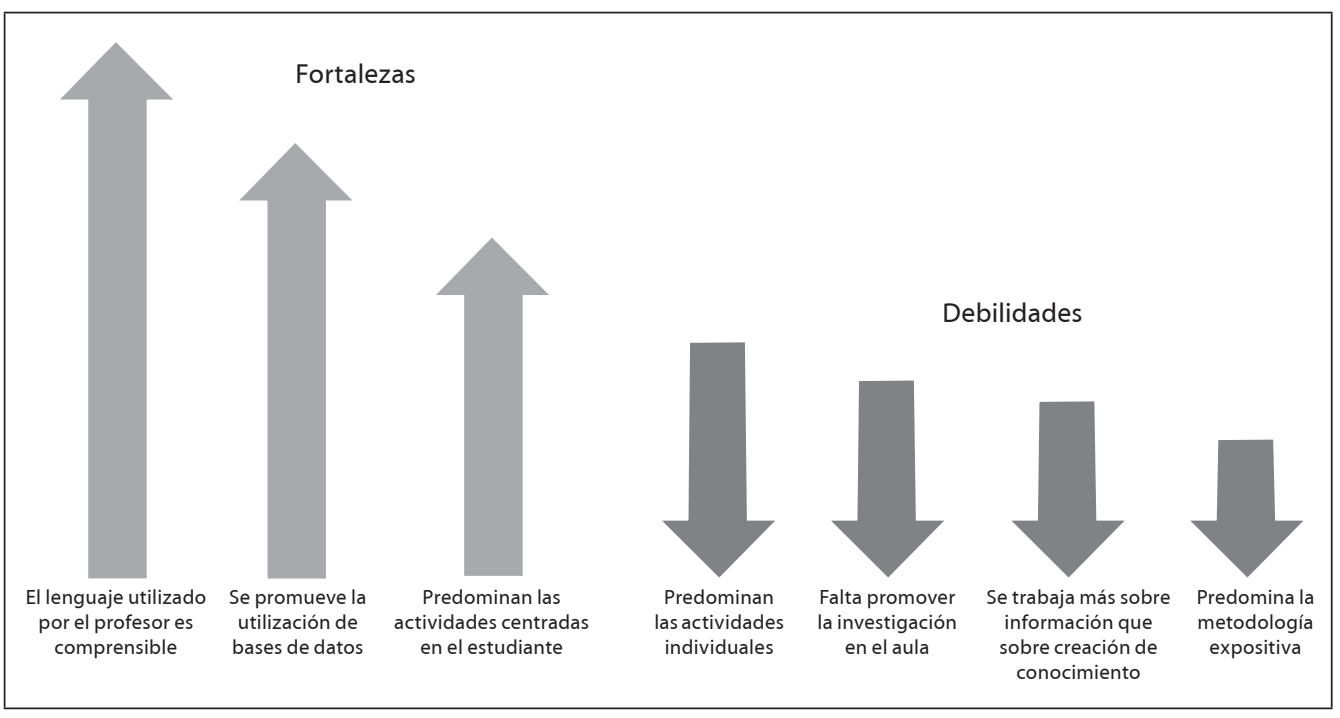

Gráfico 9. Debilidades y fortalezas en el método utilizado en los proyectos de aula Fuente: elaboración propia

En el análisis de los microcurrículos, se pudo determinar que los métodos utilizados por los profesores siguen siendo tradicionales, pues el método expositivo se encuentra en el 50\% de los proyectos de aula, seguido del trabajo individual de los estudiantes con el 35\%. Métodos alternativos como el problémico solo se encuentran en el $7 \%$ de los proyectos; el debate y la confrontación, en el 4\%; y el método investigativo en el $4 \%$.

Si se tiene en cuenta que los modelos problematizadores se fundamentan en el diálogo, los resultados del análisis de los métodos utilizados por los profesores nos permiten concluir que no promueven la comunicación en el aula y, como diría Freire, premian los comunicados, lo que los ubica en modelos tradicionales y no en los alternativos.

Para los estudiantes, el método empleado en el aula tiene diferentes apreciaciones: por un lado, un alto porcentaje de estudiantes (69\%) considera que el lenguaje utilizado hace comprensibles los contenidos, el 58\% considera que se promueve la utilización de bases de datos bibliográficas y el 52\% considera que priman las actividades centradas en el estudiante sobre las actividades centradas en el profesor. Pero por otro lado, el $46 \%$ de los estudiantes considera que priman las actividades individuales sobre las grupales, lo que va en contravía de un modelo problematizador; solo el 44\% considera que se promueve la investigación en 
el aula y el $62 \%$ considera que se trabaja más sobre información que sobre la construcción de conocimientos, lo que permitiría pensar que, aunque el estudiante siente que sus profesores saben comunicar bien los contenidos, aún tienen dificultades para aplicar métodos propios del modelo curricular adoptado por el programa.

\section{v. Estrategias didácticas}

Son el conjunto de actividades desarrolladas en el aula y por fuera de ella y en las cuales se concreta el método utilizado para lograr los objetivos. En un modelo curricular problematizador, deben primar estrategias centradas en el estudiante, lo que, según Lina Escalona-Ríos (2008, p. 144), implica un cambio en las estrategias de enseñanza para centrar el trabajo en el estudiante, lo cual lo compromete con su aprendizaje y con la generación de nuevo conocimiento. En este contexto, el profesor se convierte en facilitador de la enseñanza y guía al alumno para obtener y a aprovechar esta, para lo cual también requiere formación. Para Elvia María González-Agudelo y Lina María GrisalesFranco (2013, p. 88), se catalogan como estrategias didácticas innovadoras o activas:

[...] todas aquellas alternativas a la clase magistral, los talleres y las exposiciones: el aprendizaje basado en problemas, clubes de revista, seminarios, estudio de casos, conversatorios, debates, salidas de campo, educación por proyectos, lluvias de ideas, elaboración de productos, diarios de campo, relatorías, informes de investigación, la conversación (preguntas y respuestas). Estrate- gias que desarrollan el espíritu científico y movilizan el pensamiento del estudiante.

Pero la propuesta de estrategias didácticas activas no sataniza la clase magistral, la cual según Miguel Ángel Zabalza:

[...] es bien valorada siempre y cuando cumpla con los siguientes condiciones: que permita tomar bien los apuntes, que ofrezca información comprensible y útil y que las clases fueran interesantes y motivadoras [...] los inconvenientes de la clase magistral radican principalmente en la dificultad para resolver muchos de los problemas que se presentan en las clases actuales: excesiva carga de contenidos, gran número de alumnos, gran heterogeneidad de los conocimientos previos, dificultad para combinar la explicación general con la atención individual (2007, p. 105).

Para un currículo en el cual se busca que la investigación sea su eje transversal es necesario desarrollar estrategias didácticas centradas en esa actividad.

En el análisis de los microcurrículos, se pudo detectar que en 29 de los 34 proyectos de aula evaluados se utiliza la clase magistral como principal estrategia didáctica; en 16, aparecen los talleres y las soluciones de ejercicios; en 12, la lectura independiente del estudiante, en 12, los debates, foros y discusiones; en 8 proyectos, se aplican los conversatorios; en 7, las exposiciones o socializaciones; en 6, las asesorías independientes del profesor; en 6, las visitas de campo o empresariales; en 4, el seminario; en 3, el 
aprendizaje basado en problemas; en 2 proyectos, se utilizan estrategias como el aprendizaje colaborativo, las reseñas y los análisis contex- tuales; y en 1 proyecto, la mayéutica, la mesa redonda, los juegos, el aprendizaje significativo, las ponencias y la construcción de modelos.

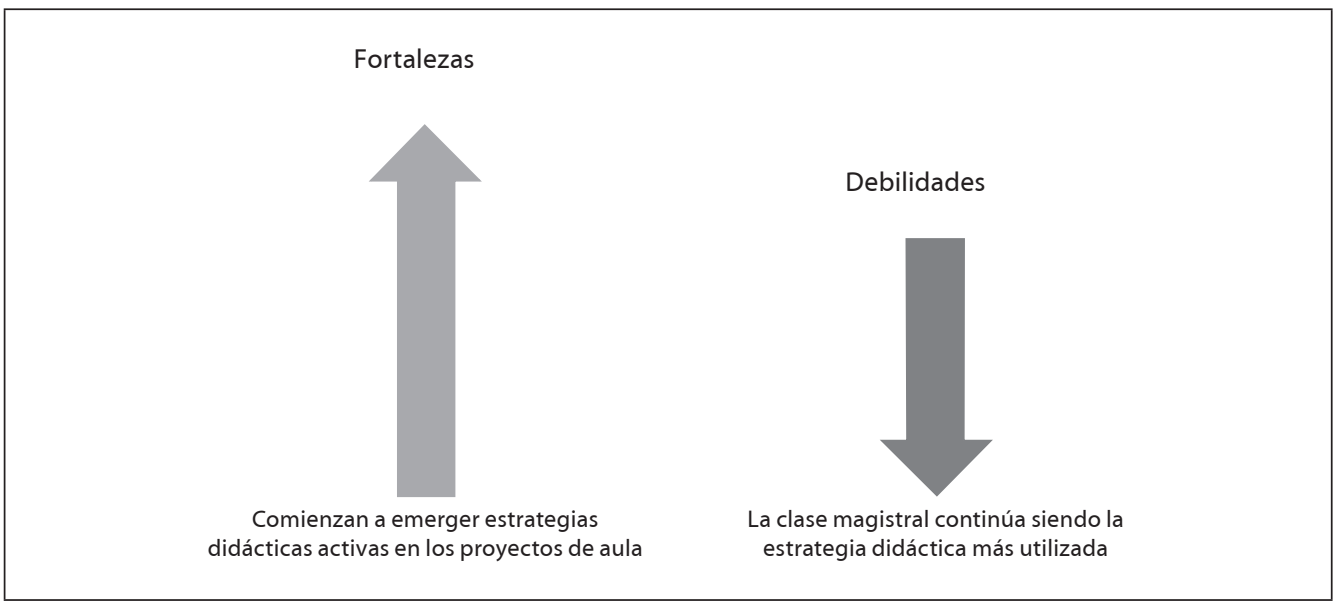

Gráfico 10. Debilidades y fortalezas en las estrategias didácticas utilizadas en los proyectos de aula Fuente: elaboración propia

En la encuesta realizada a los estudiantes, el $77 \%$ de ellos considera que la clase magistral es la estrategia didáctica más utilizada; en segundo lugar, se señala el estudio de casos; en tercer lugar, los diálogos; en cuarto lugar, la exposición; en quinto lugar, el seminario; en sexto lugar, el trabajo de campo y por último, el club de revista.

De los resultados anteriores se puede concluir que las estrategias didácticas tradicionales como la clase magistral, las exposiciones, los ejercicios y casos resueltos en el aula siguen estando en primer lugar de utilización por los profesores y, aunque se comienzan a utilizar algunas de las estrategias activas, en muy pocos proyectos se vinculan. Resulta muy contundente la percepción de los estudiantes sobre el magistrocentrismo $y$, aunque venimos insistiendo en que la clase magistral no es negativa per se, es importante hacer un trabajo muy riguroso sobre la didáctica adecuada para el modelo curricular del programa.

\section{vi. Medios}

Son los objetos utilizados en el proceso docente-educativo para que, de una manera más eficaz y eficiente, los estudiantes puedan apropiarse del contenido, adquirir habilidades, desarrollar valores, ejecutar el método, alcanzar el objetivo y solucionar el problema. Para González (s.f.) "con los medios se transita el método y los medios son portadores de contenidos. A través de los medios de enseñanza se podría llegar al conocimiento a partir de la información". Como medios tradicionales se señalan los tableros, los libros, los documentos y las diapositivas, entre otros. Como medios innovadores se pueden nombrar las tecnologías de información 
y comunicación, TIC. Para Patricia Jaramillo, Patricia Castañeda y Martha Pimienta Jaramillo (2009) y Angelo Benvenuto-Vera (2003) (citados por Duque \& González, 2013, p.3), las TIC:

$[\ldots]$ se entienden como el conjunto de herramientas tecnológicas mediante las cuales se adquiere, almacena, produce, recupera, registra y finalmente se transmiten o comunican datos, información y contenidos en forma de texto, imágenes y sonido, soportados en ambientes web y en la internet.

De acuerdo con Miguel Ángel Zabalza, “a los profesores ya no nos vale con ser buenos manejadores de libros, las fuentes de información y los mecanismos para distribuirlas se han informatizado y resulta difícil concebir un pro- ceso didáctico en la universidad sin considerar esta competencia docente" (2007, p. 92). Sin desconocer la capacidad que tienen las nuevas tecnologías para transformar lo que pasa en el aula, Zabalza señala:

[...] una queja habitual en el ámbito didáctico es que los materiales multimedia disponibles son de muy baja calidad, reproduciendo modelos de enseñanza-aprendizaje de tipo conductista y que generan escasos retos intelectuales para quienes los manejan. Se diría por tanto, que el progreso tecnológico queda reducido, a veces, a la incorporación de soportes novedosos, mientras que la práctica didáctica no solo no mejora sino que podría incluso estar en franco retroceso (2007, p. 93).

\section{Fortalezas}

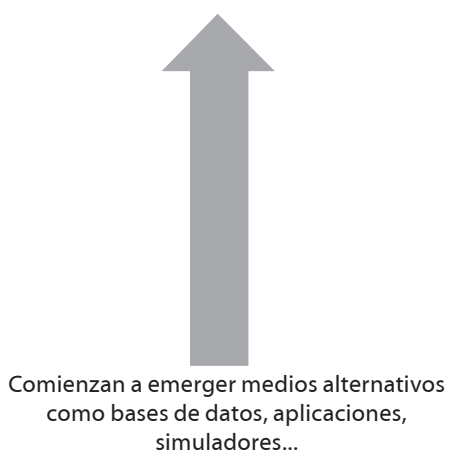

Debilidades

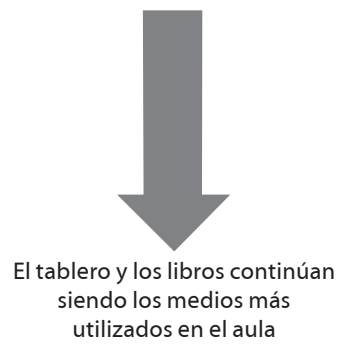

Gráfico 11. Debilidades y fortalezas en los medios utilizados en los proyectos de aula Fuente: elaboración propia 
En el análisis de los microcurrículos se pudo determinar que los libros, documentos y revistas son señalados como el medio más utilizado en el aula (20 proyectos) seguido por las diapositivas (16), el tablero (13) y los videos (13). Medios tecnológicos como el correo electrónico (8), internet (6) y la plataforma virtual Moodle (6) son utilizados en algunos proyectos de aula. Otros medios señalados con baja utilización son las bibliotecas y bases de datos, salas de cómputo, aplicaciones computacionales, simuladores, boletines y blogs.

La alta presencia de medios tradicionales como el libro y el tablero (o su nueva versión, las diapositivas) también da señales de la persistencia de clases tradicionales. De cualquier forma, la analítica respecto de los medios no puede excluir la didáctica y el método. Un medio considerado tradicional podría hacer muy dúctil un presupuesto alternativo y, a su vez, un medio alternativo podría estar siendo utilizado para un fin pedagógico anclado en lo tradicional u obsoleto.

\section{vii. Espacios}

Para Carlos M. Álvarez de Zayas y Elvia María González-Agudelo:

\footnotetext{
la forma dentro del proceso docente-educativo se encarga de los aspectos organizativos más externos del proceso como son la distribución de los estudiantes en relación con el profesor y la asignación de intervalos de tiempo en correspondencia con el contenido por asimilar y el objetivo por alcanzar; ello se denomina organización espacial y temporal del proceso, respectivamente (2002, p. 59).
}

Pero el espacio tiene un papel muy importante dentro del proceso formativo, según Miguel Ángel Zabalza (2007, p. 99), la calidad de los espacios acaba teniendo una influencia notable en el nivel de identificación personal no solo con el espacio en sí mismo sino con la propia institución a la que pertenece, en las alternativas metodológicas que el profesor pueda utilizar, en el nivel de implicación de los estudiantes y en el nivel de satisfacción de profesores y estudiantes. Al final, está claro que los espacios de aprendizaje son mucho más que un lugar neutral y sin significado en el que llevamos a cabo tareas docentes igualmente neutras y descontextualizadas que podrían llevarse a cabo en cualquier lugar.

Para Miguel Ángel Zabalza:

$$
\begin{aligned}
& \text { la única posibilidad de transformar las ac- } \\
& \text { tuales metodologías didácticas basadas pre- } \\
& \text { ponderantemente en la lección magistral } \\
& \text { (y en general los modelos docentes centrados } \\
& \text { en la acción del profesor) pasa por un tipo } \\
& \text { de organización diferente de los espacios y } \\
& \text { los recursos, de forma que lleguen a cons- } \\
& \text { tituir auténticos ambientes de aprendizaje } \\
& \text { en los que los alumnos pudieran desarrollar } \\
& \text { un estilo de aprendizaje más autónomo, más } \\
& \text { diversificado y con referentes situacionales } \\
& \text { que faciliten tanto la comprensión de los } \\
& \text { nuevos aprendizajes como su posterior evo- } \\
& \text { cación (2007, p. 99). }
\end{aligned}
$$

Sin embargo, en una institución como la Universidad de Antioquia, los espacios tienen un punto de análisis que no se puede dejar pasar y tiene qué ver con el número de estu- 
diantes por curso y la frecuente utilización de auditorios o salones muy grandes para las clases. De acuerdo con Miguel Ángel Zabalza:

los estudios internacionales en torno a clases numerosas han dejado claros algunos aspectos importantes en relación al desarrollo de una docencia de calidad. Algunas de las conclusiones de los estudios son preocupantes y merecen ser tomadas en consideración. Por ejemplo que el fracaso escolar y el abandono se incrementan notablemente. Que el contacto entre profesor y alumno (individual) acaba siendo mínimo, que ello hace imposible, de facto, esa interacción colaborativa entre docente y alumnos que se produce únicamente en la medida en que el profesor los conoce y puede seguir su proceso de aprendizaje. Esta característica del conocimiento individual de los estudiantes ha sido señalada como uno de los rasgos de calidad de la enseñanza universitaria y una de las competencias básicas para llegar a ser un docente universitario de calidad. Adicionalmente señala que los grupos masivos provocan además, el sentimiento de anonimato en los estudiantes que suele conllevar, en algunos, reacciones de miedo e inseguridad (lo cual es la antítesis de una enseñanza de calidad). Añádase a ello las dificultades para hacer preguntas. Los grupos grandes suelen imponer más, sobre todo a los alumnos más tímidos e inseguros y tienden a propiciar una actitud pasiva y receptiva por parte del alumnado en general (2007, pp. 115-116).

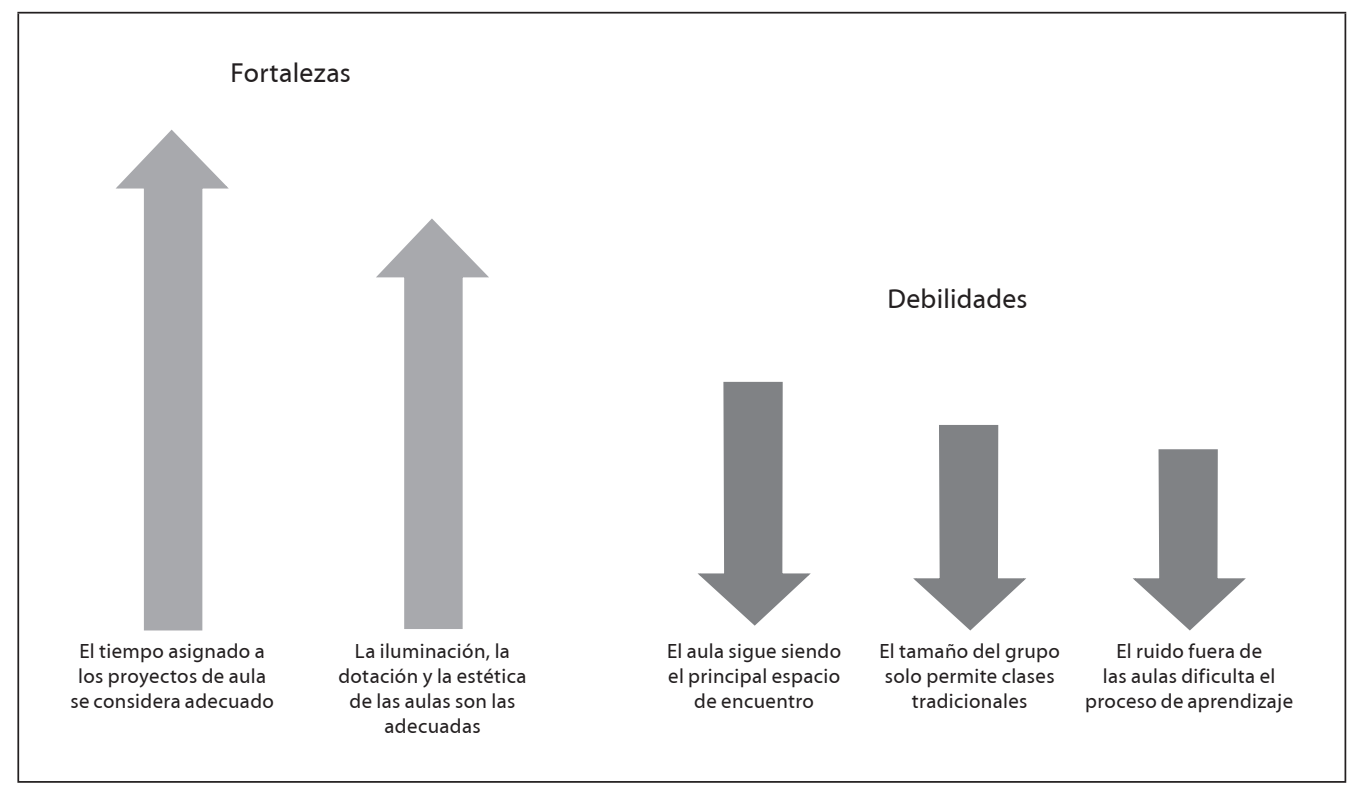

Gráfico 12. Debilidades y fortalezas en los espacios y tiempos utilizados en los proyectos de aula Fuente: elaboración propia 
En el análisis de los microcurrículos, se encontró que 20 de los 34 proyectos de aula evaluados se ofrecen en auditorios, que en promedio tienen entre 80 y 90 estudiantes. Todos los proyectos de aula señalan el aula de clase como el principal espacio de encuentro. Otros espacios utilizados en algunos proyectos de aula son: empresas (8), espacios virtuales (6), bibliotecas y otros espacios de la universidad (4), oficina de los profesores (2), salas de cómputo (2), laboratorios financieros (1), archivo histórico (1).

En la encuesta realizada a los estudiantes, los resultados muestran que el $78 \%$ de estos considera que el tamaño de los grupos es adecuado para desarrollar las metodologías utilizadas en el proyecto de aula y en una calificación de 1 a 5 le otorgan un 4,2 a la iluminación, 4 a los medios que tiene el aula, 3,9 a los olores que se perciben, 3,8 a la dotación, 3,5 a la estética y a la comodidad, 3,3 a la ventilación y 3 al ruido que se siente en los espacios utilizados para las clases.

Con respecto al tiempo presencial de los cursos, el 63\% de los estudiantes considera que es suficiente, el $23 \%$ que es más que suficiente y solo el 10\% considera que no es suficiente.

Los resultados del trabajo de campo nos permiten concluir que los espacios utilizados en la mayoría de los proyectos de aula son propicios para la aplicación de metodologías tradicionales de enseñanza, en las que prima el salón de clase con grupos grandes, donde se genera poca interacción entre el estudiante y el profesor. Pero lo más preocupante de los resultados es que este tipo de espacios son bien valorados por los estudiantes, lo que puede tener varios cuestionamientos: ¿Se acostumbraron a este tipo de esquemas espaciales y no reconocen otro? ¿Prefieren el anonimato a la interacción individual con sus profesores? ¿Es este el espacio más adecuado para desarrollar en el estudiante las competencias científicas que plantea el modelo curricular? ¿Ante la dificultad de tener un referente alternativo suavizan la evaluación del espacio actual?

\section{viii. Evaluación de aprendizajes}

La evaluación en nuestros modelos educativos representa el proceso de certificación mediante el cual se comprueba que el estudiante alcanzó los objetivos propuestos y es capaz de resolver los problemas planteados en el proyecto de aula. Para Elvia María González-Agudelo, María Isabel Duque-Roldán, Lina María Grisales-Franco, Alberto León Gutiérrez-Tamayo, Mónica Moreno-Torres y Hugo Sánchez-Fajardo (2013), el gran drama de la evaluación habitual es que ha acabado independizándose del proceso formativo como una pieza aislada y autosuficiente de la estructura curricular. Se diría que la enseñanza y la actividad formativa van por un lado y la evaluación va por otro. Se evalúa solo al final de cada período y simplemente para contrastar el nivel de aprendizaje alcanzado. De esta manera, la evaluación solo califica, mas no se inserta en el proceso formativo como un insumo para la decisión.

Para la Organización de las Naciones Unidas para la Educación, la Ciencia y la Cultura, UNESCO (1998), se requieren nuevos métodos de evaluación de los aprendizajes, que pongan a prueba no solo la memoria sino también las facultades de comprensión, la aptitud para las labores prácticas y la creatividad. El trabajo de 
Betty Collis y Jef Moonen (2011) y de Carole Leathwood y David Phillips (2000), citados por Elvia María González-Agudelo, María Isabel Duque-Roldán, Lina María Grisales-Franco, Alberto León Gutiérrez-Tamayo, Mónica
Moreno-Torres y Hugo Sánchez-Fajardo (2013, p. 64) resaltan la importancia de la evaluación formativa y de otros modos de evaluar como la gestión del trabajo en proyectos y la creación de portafolios digitales.

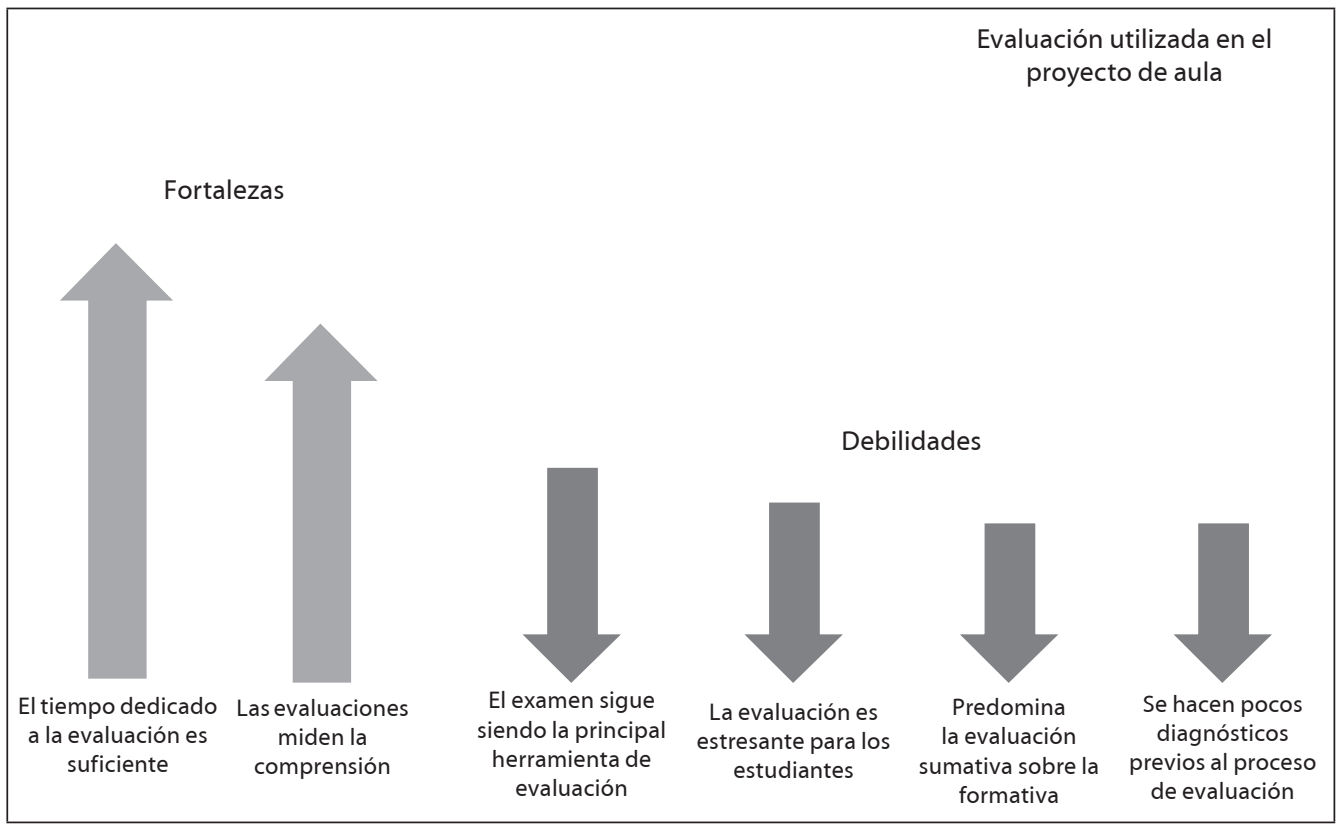

Gráfico 13. Debilidades y fortalezas en la evaluación utilizada en los proyectos de aula Fuente: elaboración propia

En el análisis de los microcurrículos, se pudo determinar que el $62 \%$ de los proyectos de aula plantea solo evaluación sumativa (parciales, quices, talleres y trabajos) en el 13\% restante, aunque también prima la evaluación sumativa, se incluyen espacios de evaluación alternativos como seminarios, análisis de discurso, estados del arte, escritura de ponencias, artículos y actividades lúdicas.

El 71\% de los estudiantes encuestados ubicó el examen como el método de evaluación más utilizado, lo cual ocurre en el $81 \%$ de los proyectos de aula incluidos en la muestra; en segundo lugar están los talleres y en tercer lugar, las exposiciones. Para el 38\% de los estudiantes no se hace un diagnóstico previo a las evaluaciones sobre las capacidades de cada alumno, el 29\% considera que sí se hace. Frente al tiempo que se dedica a las evaluaciones, el 57\% considera que es suficiente, el 55\% considera que las evaluaciones miden en primer lugar la comprensión del estudiante; en segundo lugar, la aplicación de conocimientos (30\%); tercer lugar, la argumentación (21\%) y en cuarto lugar, la memoria. En el 83\% de los proyectos de aula, la evaluación resulta estresante para los estudiantes. 


\section{8}

En el aspecto evaluativo también se hacen presentes las concepciones tradicionales pues se siguen utilizando evaluaciones sumativas tipo examen o parcial como la principal herramienta y se dejan de lado estrategias evaluativas que fomenten el desarrollo de competencias científicas en los estudiantes y que apoyen el proceso de enseñanza-aprendizaje como diagnóstico e intervención para mejorar los propósitos de formación.

\section{El profesor}

El profesor es un componente esencial de todo proceso pedagógico, curricular y didáctico. En modelos alternativos, el profesor debe tener un rol diferente. Para Peter T. Knight (2006, p. 38), "su modelo de razonamiento y acción pedagógica abarca comprender el entorno y lo que ha de enseñarse, para prepararlo, representarlo y transformarlo". Este autor señala que el profesor no solo debe conocer lo que enseña, sino que debe tener conocimientos pedagógicos, curriculares, de los aprendices y sus características, del contexto educativo sus fines, propósitos y valores.

En modelos alternativos, el profesor ejerce su función como dice Paulo Freire en la relación interpersonal, en el diálogo; no hacerlo significa para este autor:

[...] llenar los educandos con los contenidos de su narración. Contenidos que son retazos de la realidad, desvinculados de la totalidad en que se engendran y en cuyo contexto adquieren sentido. En esas disertaciones la palabra se vacía de la dimensión concreta que debería poseer y se transforma en una palabra hueca, en verbalismo alienado y alienante.

De ahí que sea más sonido que significado

y, como tal, sería mejor no decirla (2005,

p. 77).

Freire, impulsor del modelo pedagógico social, sostiene que el pensamiento del educador solo gana autenticidad en la autenticidad del pensar de los educandos, mediatizados ambos por la realidad y, por ende, en la intercomunicación. Por esto mismo, el pensamiento de aquel no puede ser un pensamiento para estos últimos, ni puede ser impuesto a ellos.

Para Miguel Ángel Zabalza (2007, p. 176), una característica o cualidad de la competencia comunicativa de los profesores se refiere a su capacidad para construir un mensaje que contenga no solo información sino también afecto. La característica fundamental de un buen profesor es transmitir "pasión" a sus alumnos. Apasionarlos por el conocimiento en general y por los asuntos concretos que desarrolla su disciplina.

La percepción de los estudiantes sobre diversos tópicos del profesor puede ser sintetizada en los siguientes enunciados:

- El 89\% de los estudiantes considera que el profesor prepara material complementario.

- El 83\% considera que el profesor recomienda fuentes adicionales a las trabajadas en clase.

- $\quad$ El 74\% considera que el profesor brinda acompañamiento por fuera del aula.

- El 52\% considera que el profesor logra un tratamiento personalizado con cada estudiante.

- El 76\% considera que el profesor es flexible con el tratamiento de los temas y el tiempo dedicado a ellos. 
- El 73\% considera que la pedagogía del profesor le facilita el entendimiento de los temas.

- El 86\% considera que el profesor prepara los temas y que hay un hilo conductor.

- El 90\% considera que el lenguaje utilizado por el profesor es comprensible.

- El 89\% considera que el profesor logra comunicarse haciendo que los enunciados sean comprensibles.

- $\quad$ El 71\% considera que el profesor motiva y genera pasión por el conocimiento.

- El 63\% considera que en el proyecto de aula se aprende un conocimiento ya hecho.

- El 86\% de los estudiantes considera que puede participar tranquilamente en la clase.

- El 86\% de los estudiantes siente que los profesores aceptan sus errores.

- El 83\% observa emoción en los profesores.

- El 87\% siente que el profesor puede dar la clase sin diapositivas.

- El 73\% de los estudiantes considera que el profesor no sigue un libro de texto y propone nuevas relaciones.

- El 84\% considera que el profesor habla de cosas científicas y también de cosas cotidianas.

- El 81\% de los estudiantes considera que el profesor parece tener sensibilidad por los problemas sociales.

- El 89\% de los estudiantes no siente temor a evaluar al profesor por posibles represalias.

- $\quad$ El 73\% de los estudiantes siente que estudia para aprehender algo.

- El $72 \%$ de los estudiantes siente que va a clase porque considera que si no va, dejara de aprender algo.
- El 76\% de los estudiantes considera que el profesor es democrático.

- El 71\% de los estudiantes considera que el profesor sabe y es buen pedagogo.

Como puede observarse, en términos generales, la práctica docente resulta bien evaluada. Esto deja un importante incentivo, pues las acciones mejoradoras contarían con agentes competentes para ser desarrolladas.

\section{d. La gestión curricular}

La gestión curricular puede ser entendida como un conjunto de procesos que se siguen para lograr los objetivos presupuestados de una determinada estructura curricular. En palabras de Elvia María González-Agudelo:
La gestión curricular planifica, organiza, regula y controla el modelo curricular para su óptima ejecución. Planifica cuando pre- vé el funcionamiento adecuado del modelo curricular para lograr los propósitos de for- mación. Organiza cuando destina tareas, au- toridad y recursos a los grupos de profesores y estudiantes que participan en el proceso, con el fin de lograr el éxito de los resultados propuestos. Regula cuando adecúa operati- vamente el proceso mediante acciones como dirigir, influir y motivar a los grupos de pro- fesores y estudiantes para que realicen las tareas fundamentales para el logro de los ob- jetivos. Controla cuando garantiza mediante normas, que el proceso de obtención de re- sultados se ejecute en la forma más eficiente (2000, p. 19). 
Fortalezas

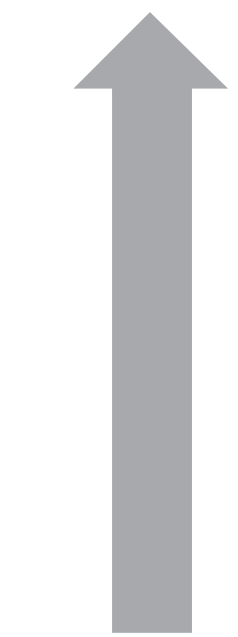

Se percibe una evaluación permanente al currículo

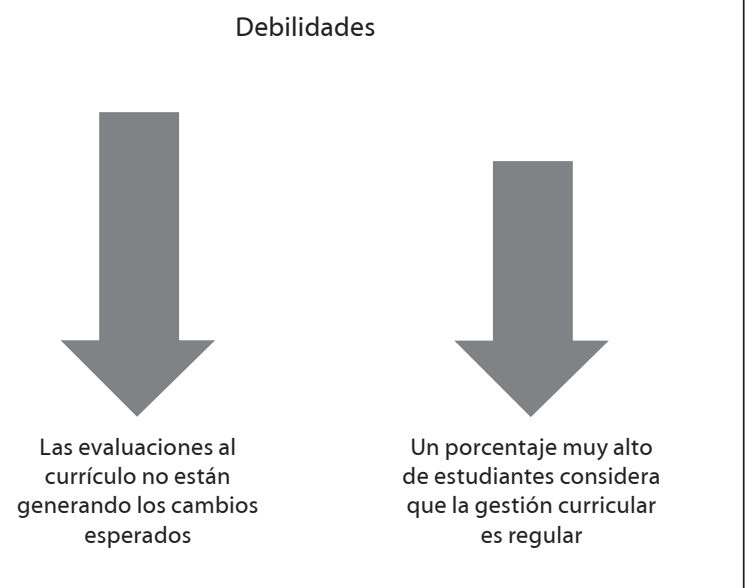

Gráfico 14. Debilidades y fortalezas en la gestión curricular Fuente: elaboración propia

Un poco más de la mitad de los estudiantes encuestados (53\%) considera que la gestión curricular realizada por el Departamento de Ciencias Contables es buena, el 39\% considera que es regular, el 5\% que es mala y el 3\% no responde. Los estudiantes también consideran en un porcentaje muy alto (37\%) que las evaluaciones solo generan cambios parciales en el plan de formación y el 34\% considera que no generan ningún cambio. Por las respuestas a estos interrogantes, se puede apreciar que los estudiantes reconocen que hay una evaluación permanente del currículo pero tienen reparos frente a los cambios y mejoras que se derivan de esta evaluación, razón por la cual la gestión curricular no resulta bien evaluada.

\section{Aperturas (o conclusiones)}

La sospecha que nos mantiene inquietos en este proceder investigativo y que es confirmada con el trabajo de campo realizado, es que la teleología del modelo pedagógico y curricular del programa de contaduría pública de la Universidad de Antioquia no se concreta totalmente en las prácticas cotidianas, es decir, en el currículo y la pedagogía viva. Y esto no quiere decir que no se hayan logrado importantes cosas en el terreno de la interdisciplinariedad, de la investigación, de la formación del profesorado, y en el desarrollo de algunos propósitos de formación en la estructura simbólica y de competencias del estudiantado. Sin embargo, que- 
remos ser muy incisivos, pues sospechamos que ello nos puede movilizar en la cualificación del currículo y en la consolidación de un proyecto educativo más complejo y mejor equipado para la disciplina y la profesión contable y para el mundo de la vida de nuestros estudiantes.

La intencionalidad de un currículo problematizador y un modelo pedagógico de los procesos conscientes está declarada en los documentos programáticos y algo de ello también aparece en los microcurrículos de los proyectos de aula. La teoría nos hace vigilar el sentido de los conceptos, para mantener una crítica permanente incluso con aquellos que nos sentimos más a gusto o con disposición a defender. La literatura desde el horizonte de la educación, la pedagogía y la teoría curricular nos propone retos para mantener viva la discusión sobre la propuesta curricular que actualmente agenciamos.

La percepción de los estudiantes nos advierte la necesidad de mejorar diversos tópicos que han sido descritos en este texto, relacionados con la organización y planificación de los proyectos de aula, la didáctica utilizada en el aula, la investigación como eje transversal, la labor docente y la gestión curricular. Pero también nos invita a triangular con otras metodologías de investigación para aproximarnos a una comprensión cada vez más decantada y refinada de lo que ocurre en las prácticas cotidianas que dan vida al currículo.

Los principales agentes llamados a mantener una actitud estudiosa y reflexiva sobre las prácticas educativas somos los docentes, quienes tenemos el deber de actuar como intérpretes de la teleología educativa del programa y principales actores en el proceso comunicativo del que deben participar los estudiantes para que sean conmovidos en su comprensión y transformación del mundo de la vida.

Esta tensión entre lo tradicional (a lo que estamos anclados) y lo contemporáneo (hacia donde debemos virar) hace parte del proceso de pensar curricularmente. Lo peor que nos puede pasar es suponer que todo funciona bien, o ni siquiera suponer, sino estar en esa pasmosa forma de vivir la docencia en cierta irreflexividad, haciendo tareas mecánicas y proponiendo muy poco en el terreno didáctico. Hasta aquí, podemos decir que hace falta una mayor interiorización y, por ende, más prácticas educativas para que la intencionalidad curricular del programa se refleje jornada tras jornada en las prácticas curriculares, pedagógicas y didácticas. Y también podemos decir que estas conclusiones están en movimiento esperando articularse a nuevas informaciones y conocimientos que las refuten o que las ratifiquen, pero en la tentativa de movilizar la propuesta educativa hacia las cualidades que más favorezcan la elección formativa del estudiante.

\section{Referencias}

Álvarez de Zayas, Carlos M. \& González-Agudelo, Elvia María (2002). Lecciones de didáctica general. Medellín: Edinalco.

Alzate, María Victoria; Gómez, Miguel Ángel \& Arbeláez, Martha Cecilia (2011). Enseñar en la universidad. Saberes, prácticas y textualidad. Bogotá: ECOE Ediciones.

Apostolou, Barbara; Dorminey, Jack W.; Hassell, John M. \& Watson, Stephanie F. 
(2013). Accounting Education Literature Review (2010-2012). Journal of Accounting Education, 31 (2), 107-161.

Barnett, Ronald (2001). Los límites de la competencia. El conocimiento, la educación superior y la sociedad. Barcelona: Gedisa Editores.

Benvenuto-Vera, Angelo (2003). Las tecnologías de información y comunicaciones (TIC) en la docencia universitaria. Theoria, Ciencia, Arte y Humanidades, Universidad del Bío Bío, Chile, 12 (1), 109-118. Disponible en: http://www.redalyc.org/articulo. oa?id=29901210

Carvalho-Betancur, Javier Alonso; CadavidArango, Luis Alberto; Zapata, Miguel Ángel; Tobón-Echeverri, Fabio León \& Duque-Roldan, María Isabel (2006). Recreando el currículo: contaduría pública. Medellín: Universidad de Antioquia.

Carvalho-Betancur, Javier Alonso \& OspinaZapata, Carlos Mario (2009). Elementos generales. Currículo Contaduría Pública Universidad de Antioquia. En Gabriel Rueda-Delgado (ed.) (2009). Enfoque y estructura curricular: Convenio de cooperación académica entre programas de contaduría pública, 47-74. Bogotá: Pontificia Universidad Javeriana.

Collis, Betty \& Moonen, Jef (2011). Flexibilidad en la educación superior: revisión de expectativas. Comunicar, Revista Científica de Comunicación y Educación, Andalucía, 37. Disponible en: http://www.revistacomunicar.com/index.php?contenido $=$ detalles\&nu mero $=37 \&$ articulo $=37-2011-03$

Duque-Roldan, María Isabel \& González-Agudelo, Elvia María (2013). Las tecnologías de información y comunicación y los nuevos modelos educativos. Informe que hace de la investigación Propuesta de políticas curriculares para la Universidad de Antioquia, informe final de investigación. Medellín: Vicerrectoría de Docencia, Universidad de Antioquia.

Escalona-Ríos, Lina (2008). Flexibilidad curricular: elemento clave para mejorar la educación bibliotecológica. Investigación Bibliotecológica, 44 (22), 143-160. Disponible en: http://www.ejournal.unam.mx/ibi/ vol22-44/IBI002204408.pdf

Flórez-Ochoa, Rafael (1994). Hacia una pedagogía del conocimiento. Bogotá: McGraw-Hill.

Freire, Paulo (1970). Pedagogía del oprimido. México: Siglo XII Editores.

Gómez-Vahos, Jovany (2002). El modelo pedagógico social, primer paso hacia un compromiso histórico real. Revista Perspectivas, 11, 29-34.

González-Agudelo, Elvia María (1999). Corrientes pedagógicas contemporáneas. Medellín: Universidad de Antioquia, Facultad de Educación.

González-Agudelo, Elvia María (2000). Un currículo basado en la solución de problemas para la formación de profesionales. Medellín: Universidad de Antioquia, Vicerrectoría de Docencia, Transformación Curricular.

González-Agudelo, Elvia María (2001). Acerca de las concepciones didácticas o del conversar sobre el conocimiento. Cuadernos Pedagógicos, Facultad de Educación, Universidad de Antioquia, Medellín, 15, 45-52.

González-Agudelo, Elvia María (s.f.). El proyecto de aula o acerca de la formación en investigación. Disponible en: http://aprendeenli- 
nea.udea.edu.co/lms/moodle/file.php/177/

Que_es_un_proyecto_de_aula_Elvia_Maria_Gonzalez.rtf

González-Agudelo, Elvia María \& GrisalesFranco, Lina María (2013). Acerca de la investigación formativa como concepto transversal para los currículos de pregrado de la Universidad de Antioquia, informe final de investigación. Grupo de Investigación DIDES, Universidad de Antioquia.

Disponible en: http://www.uptc.edu.co/ eventos/2013/cf/cipni/memoria/memorias_ preliminar_cip3.pdf

González-Agudelo, Elvia María (dir.); DuqueRoldán, María Isabel; Grisales-Franco, Lina María; Gutiérrez-Tamayo, Alberto León; Moreno-Torres, Mónica \& Sánchez-Fajardo, Hugo (2013). Propuesta de políticas curriculares para la Universidad de Antioquia, informe final de investigación. Medellín: Universidad de Antioquia, Vicerrectoría de Docencia.

González-Agudelo, Elvia María; Upegui-Velásquez, María Eugenia; Duque-Roldán, María Isabel \& Álvarez-Osorio, Martha Cecilia (2009). Sobre la evaluación de currículos en la educación superior. Medellín: Departamento de Ciencias Contables, Centro de Investigaciones y Consultorías, Facultad de Ciencias Económicas, Universidad de Antioquia.

Hernández, Carlos Augusto (1996). Educación y comunicación. Pedagogía y cambio cultural. Nómadas, 5. Disponible en: http://www. redalyc.org/pdf/1051/105118998005.pdf

Jaramillo, Patricia; Castañeda, Patricia \& Pimienta, Martha (2009). Qué hacer con la tecnología en el aula: inventario de usos de las TIC para aprender y enseñar. Educación y Educadores, Universidad de la Sabana, Bogotá, 12 (2), 159-179. Disponible en: http://www.redalyc.org/articulo. oa?id=83412219011

Knight, Peter T. (2006). El profesorado de educación superior, formación para la excelencia. Madrid: Narcea Ediciones.

Leathwood, Carole \& Phillips, David (2000). Developing Curriculum Evaluation Research in Higher Education: Process, Politics and Practicalities. Higher Education, 40, 313-330. Disponible en: http://link.springer.com/article/10.1023\%2FA\%3A1004183 527173\#page-1

León-Paime, Edison Fredy (2013). La investigación en educación contable: breve historia y revisión internacional. Lúmina, 14, 228-261. Disponible en: http://www. umanizales.edu.co/publicaciones/campos/ economicas/lumina/recursos/14/9.pdf

Magendzo-Kolstrein, Abraham (1991). Currículum y cultura en América Latina. Santiago de Chile: Programa Interdisciplinario de Investigación en Educación, Editorial PIIE.

Morin, Edgar; Ciurana, Emilio Roger \& Motta, Raúl Domingo (2003). Educar en la era planetaria. Barcelona: Editorial Gedisa.

Not, Louis (1979/2000). Las pedagogías del conocimiento. Bogotá: Fondo de Cultura Económica, FCE.

Organización de las Naciones Unidas para la Educación, la Ciencia y la Cultura, UNESCO (1998). Declaración Mundial sobre la Educación Superior en el siglo XXI: visión y acción. Conferencia Mundial sobre la Educación Superior. París. Disponible 
en: http://www.unesco.org/education/ educprog/wche/declaration_spa.htm

Organización de las Naciones Unidas para la Educación, la Ciencia y la Cultura, UNESCO (2009). Declaración Mundial sobre la Educación Superior 2009: la nueva dinámica de la educación superior y la investigación para el cambio social y el desarrollo. París. Disponible http://unesdoc.unesco.org/ images/0018/001832/183277s.pdf

Ospina-Zapata, Carlos Mario (2009). Educación Contable en Colombia. Sentires de algunos actores y la educación contable como acción educativa. Contaduría Universidad de Antioquia, 55, 11-40. Disponible en: http:// aprendeenlinea.udea.edu.co/revistas/index. php/cont/article/view/16336/14169

Quiroz-Posada, Ruth Elena \& Monsalve-Díaz, Ana Elsy (2004). Sistema didáctico tradicional o alternativo. Cuadernos Pedagógicos, Facultad de Educación, Universidad de Antioquia, Medellín, 24, 109-116.

Rojas, William \& Ospina, Carlos Mario (2011). Consideraciones sobre el sentido de un proyecto educativo en contaduría pública. Cuadernos de Administración, 27 (45), 4560. Disponible en: http://www.redalyc.org/ articulo.oa?id $=225019868004$

Rueda-Delgado, Gabriel (2009). Enfoque y estructura curricular: Convenio de cooperación académica entre programas de contaduría pública. Bogotá: Pontificia Universidad Javeriana. Universidad de Antioquia, Departamento de Ciencias Contables (2001). Propuesta de transformación curricular del Departamento de Ciencias Contables. Medellín: Universidad de Antioquia. Disponible en: http://huitoto. udea.edu.co/programacionacademica/ contenido/IPPA/ACUERDOS\%20 TRANSFORMACION\%20CURRICULAR/ documento-maestro-rector/Doc\%20 Rector\%20\%20Contaduria.pdf Willits, Stephen D. (2010). Will More Liberal Arts Courses Fix the Accounting Curriculum?, Journal of Accounting Education, 28 (1), 13-25.

Zabalza, Miguel Ángel (2007). Competencias docentes del profesorado universitario. Calidad y desarrollo profesional. Madrid: Narcea Ediciones.

Zubiría, Julián de (2006). Los modelos pedagógicos. Hacia una pedagogía dialogante. Bogotá: Magisterio Dialogante.

- Fecha de recepción: 18 de marzo de 2015

- Fecha de aceptación: 29 de mayo de 2015

- Disponible en línea: 30 de agosto de 2015

\section{Para citar este artículo}

Duque-Roldán, María Isabel \& Ospina-Zapata, Carlos Mario (2015). Elementos para discusión sobre el estado actual de la propuesta curricular del programa de contaduría pública de la Universidad de Antioquia. Cuadernos de Contabilidad, 16 (41), 355-394. http://dx.doi.org/10.11144/ Javeriana.cc16-41.edea 